\title{
El concepto constitucional de familia en América Latina. Tendencias y proyecciones ${ }^{*}$
}

\section{DAVID FABIO ESBORRAZ}

Resumen: La dinámica de "constitucionalización” e "internacionalización” de los ordenamientos en Latinoamérica ha incidido directa y profundamente en el concepto de familia al imponer una relectura de las relaciones familiares a la luz de los derechos fundamentales. Como consecuencia de este nuevo paradigma constitucional se constata que en la mayor parte de los ordenamientos de Latinoamérica, aunque con diferentes matices, se ha pasado: i) de un modelo de familia "totalizante" a otro más "democrático", donde se trata de conciliar el interés familiar con el interés personal de sus integrantes, y ii) de un modelo

Este artículo presenta la investigación expuesta en la Conferencia introductiva de la Mesa de Trabajo n. ${ }^{\circ} 2$ sobre "Familia y Derechos Humanos" del vi Seminario Internacional de Estudios Jurídicos sobre "Constitucionalización del Derecho de Familia" (Xalapa, México, 9- - Io de octubre de 20I4) organizado por la Universidad Veracruzana, bajo la dirección de los profesores Aníbal Guzmán Ávalos y María del Carmen Valdés Martínez. El autor agradece muy especialmente a los Dres. Omar Augusto Bautista Quisbert (Bolivia), Juan Carlos Prado (Ecuador), Carlos Podreschi (Panamá), Sheraldine Pinto Olivera (Venezuela), Luis Carlos Sánchez Hernández (Colombia), Adolfo Vallejos (Paraguay) y Angela Viero (Brasil) por la colaboración prestada en relación con la información referida a sus respectivos países.

Fecha de recepción: 29 de mayo de 2015 . Fecha de aceptación: 3 I de agosto de 2015.

Para citar el artículo: D. F. Esborraz, "El concepto constitucional de familia en América Latina. Tendencias y proyecciones", Revista de Derecho Privado, Universidad Externado de Colombia, n. ${ }^{\circ}$ 29, julio-diciembre de 201 5, pp. I 5-55. DOI: http://dx.doi.org/Io. I 860I/o I $234366 . n 29.02$

** Doctor en "Sistema Jurídico Romanista y Unificación del Derecho" de la Università degli Studi di Roma 'Tor Vergata'. Investigador del Istituto di Studi Giuridici Internazionali (I.S.G.I) del Consiglio Nazionale delle Ricerche (C.N.R), con funciones en el Centro di Studi Giuridici Latinoamericani (C.S.G.L.A) de la Università degli Studi di Roma 'Tor Vergata'/C.N.R., Italia. Contacto: esborraz@juris.uniromaz.it 
"único" de familia al reconocimiento de una "pluralidad" de modelos familiares, todos ellos dignos de igual tutela.

Palabras Clave: Neoconstitucionalismo latinoamericano, "constitucionalización" e "internacionalización” del derecho de familia, “democratización” de la familia, "pluralidad" de modelos familiares, familia matrimonial, familia convivencial, familia homoparental, familia monoparental, familia ensamblada, familia ampliada, familia indígena.

\section{The constitutional concept of family in Latin America. Tendencies and projections}

Aвstract: The processes of "constitutionalization" and "internationalization" have deeply affected the concept of family by imposing a re-reading of family relationships in light of 'Fundamental' Rights. Although there are some exceptions, in general, as a consequence of this new constitutional paradigm is appears that, most Latin America legal systems have gone: i) from a 'totalitarian' family model to a more 'democratic' one, where there is an attempt to harmonize the family interests with the personal interests of all its members; and ii) from a 'unique' family model to the recognition of a 'plurality' of family models, all equally worthy of protection.

Keywords: Latin American neoconstitutionalism, "constitutionalization" and "internationalization" of family law, "democratization" of the family, "plurality" of family models, matrimonial family, "convivial" family, "homoparental" family, single parent family, blended family, extended family, indigenous family.

Sumario: Introducción. i. La familia en el denominado "nuevo constitucionalismo latinoamericano". A. Del "Estado 'legal' de derecho" al "Estado 'constitucional' de derecho". B. La "constitucionalización” e "internacionalización” del derecho de familia. II. Los diversos modelos familiares resultantes del derecho constitucional latinoamericano vigente. A. La familia matrimonial. B. La familia convivencial. C. La familia homoparental. D. La familia monoparental. E. La familia ensamblada. F. La familia ampliada. G. La familia indígena. Conclusiones. Bibiografía.

\section{Introducción}

Debemos precisar desde el inicio que por "concepto constitucional" de familia en América Latina no entendemos solo la noción que de la misma se puede inferir de los textos de las Constituciones formales, sino también la que se deduciría 
de los respectivos "bloques de constitucionalidad", que a los fines que aquí nos interesan -y sin desconocer las distintas acepciones que se le han asignado a esta expresión en el ámbito del derecho constitucional comparado ${ }^{\mathrm{I}}-$ consideramos comprensivos, además, de: i) los textos de los instrumentos internacionales en materia de derechos humanos a los que se les reconozca jerarquía constitucional (así como de las interpretaciones de los órganos internacionales encargados de monitorear y/o de hacer cumplir estos últimos) ${ }^{2}$, y ii) las decisiones de los órganos nacionales competentes para llevar a cabo el control de constitucionalidad (sea este difuso, concentrado o mixto).

Sin embargo, es necesario asimismo puntualizar de antemano que la familia no ha sido conceptualizada expresamente en ninguna de las Constituciones de América Latina -tanto históricas como vigentes- ni en ninguno de los instrumentos internacionales sobre derecho humanos que integran el referido "bloque de constitucionalidad" (como tampoco lo ha sido, por lo general, en el derecho secundario o derivado de la Región que se ocupa de regular sistemáticamente las relaciones de familia 3 ). Se trata, en consecuencia, de una noción implícita

I Se trata de una expresión acuñada en el derecho constitucional francés en el que se habla de "bloc de constitutionnalitê" para referir al conjunto de normas a tener en cuenta para llevar a cabo el control de constitucionalidad de las leyes por parte del Conseil constitutionnel, conjunto que estaría integrado por el articulado de la Constititución francesa de i 958, por los instrumentos a los que reenvía el Preámbulo de la misma (la Declaración de los Derechos del Hombre y del Ciudadano de I 789, el Preámbulo de la Constitución francesa de I 946 y la Carta del Medio Ambiente de 2004) y por los principios fundamentales reconocidos por las leyes de la República (cfr. en este sentido, p. ej., Louis Favoreau, "Le principe de constitutionnalité. Essai de définition d'après la jurisprudence du Conseil constitutionnel”, en Recueil d'études en hommage à Charles Eisenmann, Paris, I977, p. 33).

$\mathrm{La} \mathrm{CBol/2009}$ refiere expresamente al "bloque de constitucionalidad", que considera "integrado por los Tratados y Convenios internacionales en materia de Derechos Humanos y las normas de Derecho Comunitario, ratificados por el país" (art. 4IO.II).

Sobre las distintas acepciones de la expresión "bloque de constitucionalidad" en el constitucionalismo latinoamericano remitimos, entre otros, a Néstor P. SAGüés, Elementos de Derecho constitucional, t. I, Buenos Aires, I999³ , pp. I4 I ss.

2 Tal como sucede, p. ej., en el denominado "Sistema interamericano de Derechos Humanos", integrado no solo por el texto de la Convención homónima sino también por las declaraciones de la Comisión y las resoluciones de la Corte Interamericana de Derechos Humanos (cfr., en este sentido, César Alfonso, "La obligatoriedad de las decisiones de la Corte Interamericana de Derechos Humanos desde la perspectiva de distintos países de América del Sur", en KaI Ambos, Ezequiel Malarino y Gisela Elsner (coords.), Sistema Interamericano de Protección de los Derechos Humanos y Derecho Penal Internacional, Montevideo, 2010 , pp. 63 ss.).

3 Solo excepcionalmente encontramos definida la familia a nivel legislativo, tal como lo hace $-\mathrm{p}$. ej.- la Ley venezolana n. $^{\circ} 38.773$ para la protección de las familias, la maternidad y la paternidad de 2007 cuando dispone que "a los efectos de esta Ley, se entiende por familia, la asociación natural de la sociedad y espacio fundamental para el desarrollo de sus integrantes, constituida por personas relacionadas por vínculos jurídicos o de hecho, que fundan su existencia en el amor, respeto, solidaridad, comprensión mutua, participación, cooperación, esfuerzo común, igualdad de deberes y derechos, y la responsabilidad compartida de las tareas que implican la vida familiar" (art. 3), o el Anteproyecto de Código de las Familias y del Proceso Familiar del Estado Plurinacional de Bolivia de 20 I3 $_{3}$, cuando la caracteriza como "el grupo social perma- 
que debe ser extraída de los datos suministrados por ese complejo de fuentes; operación esta que muchas veces, cuando es llevada a cabo por los órganos encargados de efectuar el control de constitucionalidad, puede constituir una decisión política (o de política del derecho) en atención a que -como veremos más adelante-, a partir de la interpretación y aplicación de plexos constitucionales similares, se arriba sin embargo a un concepto de familia en cada caso diferente (es decir: más amplio, en algunos ordenamientos, y más restringido, en otros) ${ }^{4}$.

\section{La familia en el denominado "nuevo constitucionalismo latinoamericano"}

\section{A. Del "Estado 'legal' de derecho" al "Estado 'constitucional' de derecho"}

La particular consideración de que es objeto la familia en la mayor parte de los textos constitucionales latinoamericanos vigentes no constituye en realidad un fenómeno nuevo, en atención a que el mismo se encontraba ya presente en las Leyes fundamentales de América Latina dictadas desde los albores del denominado "Constitucionalismo social de derecho" puesto en marcha por la CMéx/ı 9 I 7 -el que vino a sustituir el "Constitucionalismo fundacional" de carácter "liberal" o "liberal-conservador" imperante en la Región desde mediados del siglo XIX- mediante la incorporación de una regulación especial sobre la institución familiar ${ }^{5}$ y a la que incluso algunas Constituciones llegaron a calificar expresamente como "sociedad natural" y/o "fundamento", "célula", "base", "elemento" o "núcleo primario" fundamental de la "sociedad" o de la "Nación".

nente, constituido por el vínculo conyugal formalizado ante el Estado o no, por el parentesco u otra forma" (art. 3.I).

4 Baste confrontar a este respecto, a mero título ejemplificativo, la jurisprudencia sobre la "familia homoparental" de la Sala Constitucional del Tribunal Supremo de Venezuela y del Tribunal Constitucional de Chile, por un lado, con la de la Corte Constitucional de Colombia, de la Suprema Corte de Justicia de México y del Supremo Tribunal Federal de Brasil, por el otro (cfr. infra II.C).

5 Cfr., p. ej., la CBr/ı 934, arts. I44-I 47; la CUru/ı 934, arts. 39-42 y 48; la CHon/ı 936, art. I 97; la CBol/1 938, arts. I3 I-I 34; la CSal/I 939, arts. 6o-6r; la CCub/1940, arts. 43-46; la CEcu/1946, arts. I62-I67 y I 7 I; la CArg/I 949, art. 37.II; la ccR/I 949, arts. 5 I-53; la CVen/I96 I, arts. 7375; la CPar/1967, arts. 8I -87 .

6 Cfr., p. ej., los arts. I 97 de la CHon/ı936; 60 de la CSal/ı 939; 37.II.pr. de la CArg/ı949; 5 I de

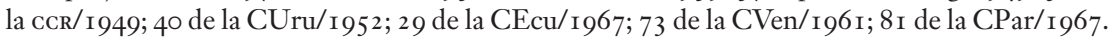
Así ya la Constitución Política de la República de Centroamérica de I92 I había dispuesto que "Se establecerá un centro técnico bajo el nombre de 'Instituto de Reformas Sociales' cuyas atribuciones y deberes serán los siguientes: [...] c) Proteger el matrimonio y la familia, como base y fundamento de la sociedad y organizar el patrimonio familiar (Homeslead)" (art. I7I). 
En la materia que aquí nos ocupa el modelo inicial de esta "primera oleada" del reformismo constitucional latinoamericano ${ }^{7}$ podría encontrarse en la Constitución de la segunda República Española de r93 I (art. 43) ${ }^{8}$, puesto que, si bien la familia estaba todavía estructurada preferentemente sobre la base del matrimonio 9 , se estableció ya por algunas Cartas constitucionales la igualdad jurídica entre ambos cónyuges ${ }^{\mathrm{IO}}$; así como también la no discriminación entre hijos matrimoniales y extramatrimoniales ${ }^{\mathrm{II}}$, con la consiguiente prohibición de dejar constancia en las actas del Registro Civil de cualquier calificación sobre la naturaleza de la filiación y/o del estado civil de los progenitores ${ }^{\mathrm{I} 2}$, y con el reconocimiento de la posibilidad de investigar la paternidad ${ }^{\mathrm{I}} 3$.

Empero, el "Constitucionalismo social latinoamericano" no se limitó a imitar a su par europeo sino que en el tema que aquí nos ocupa -así como en muchos otros- incluso lo superó, al comprender expresamente dentro de la noción de familia a las "uniones de hecho", cuyos efectos algunos textos constituciona-

7 Emplean esta expresión Roberto Gargarella y Christian Courtis, El nuevo constitucionalismo latinoamericano: promesas e interrogantes, cepal, Serie Políticas Sociales, n. ${ }^{\circ}$ I 53, Santiago de Chile, 2009 , p. 25.

8 Se trata de un modelo similar al propuesto en Europa, algunos años antes, por la Constitución alemana de Weimar de I9 I9 (arts. I I9 y I 20), seguido luego -aunque con algunos matices diferentes- por la Constitución italiana de r 948 (arts. 29-3 I), la Constitución alemana de Bonn de 1949 (art. 6) y, también, por las Constituciones portuguesa de i 976 (art. 36) y española de I 978 (art. 39).

Acerca de la influencia de la CEsp/r93 I sobre las Constituciones de América Latina cfr., en general, Javier Pérez Royo, "Influencia del constitucionalismo español en el constitucionalismo iberoamericano", en Miguel Carbonell, Jorge Carpizo y Daniel Zovatto (coords.), Tendencias del constitucionalismo en Iberoamérica, México, D.F., 2009, p. 42 I.

9 Cfr., p. ej., la CPer/ı 933, art. 5 I; la CBra/ı934, art. I44; la CBol/ı 938, art. I3 I; la CSal/ı939, art. 6o; la CCub/ı 940, art. 43; la CArg/ı 949, art. 37.II. I; la ccr/I 949, art. 52; la CVen/ı 96ı, art. 73; la CEcu/I967, art. 29; la CPar/ı967, art. 8 I. Al cual, incluso, se lo declaraba objeto de "protección” o "fomento" especial por parte de la ley o del Estado (cfr., p. ej., la CPer/ı933, art. 5 I; la CBra/ı 934, art. I44; la CSal/ı 939, art. 69; la CCub/ı 940, art. 43; la CBol/ı 945, art. I 3 I; la CEcu/ı 946, art. I63; la CArg/ı 949, art. 37.II.pr.; la CHon/ı 957, art. 99; la CVen/ı 96 I, art. 73; la CPar/I 967 , art. 8I), aunque admitiéndose expresamente en algunos casos la posibilidad de disolver el vínculo matrimonial (cfr., p. ej., la CCub/ı 940, art. 43; la CHon/ı 957, art. I Io). Las únicas Cartas constitucionales latinoamericanas que, en cambio, habían dispuesto expresamente la indisolubilidad del matrimonio eran las Constituciones históricas de Brasil (la CBra/ı934, art. I44; la CBra/ı937, art. I 24; la CBra/ı946, art. I63 y la CBra/ı967, art. I67.I).

ı Cfr., p. ej., la CCub/ı 940, art. 43; la CBol/ı945, art. I3 I; la CArg/ı 949, art. 37.II. I; la cCR/I949, art. 52; la CSal/I950, art. i80; la CMéx/ı91 7-ı974, art. 4.

i I Cfr., p. ej., la CUru/ı 934, art. 41; la CBra/ı 937, art. I 26; la CBol/ı938, art. I32; la cCR/ı949, art. 53; la CSal/ı950, art. i 8 i; la CHon/ı 957, art. I02; la CCub/ı959, art. 44 .

I 2 Cfr., p. ej., la CEcu/ı946, art. I65; la ccR/ı 949, art. 54; la CSal/ı950, art. i 8 i; la CHon/ı 957 , art. I02; la CCub/ı959, art. 44; la CPar/ı 967 , art. 86.

I 3 Cfr., p. ej., la CBra/ı937, art. I 26; la CBol/ı 945, art. I32; la cCR/ı 949, art. 53; la CSal/ı950, art. I8 I; la CHon/ı957, art. ı04; la CCub/ı959, art. 44; la CVen/ı 96 I, art. 75. 
les equipararon directamente a los del matrimonio civil ${ }^{14}$, y a la filiación por adopción ${ }^{15}$. Asimismo, muchas Constituciones latinoamericanas prestaron una particular atención -entre otras muchas cuestiones ${ }^{16}$ - a la protección del patrimonio familiar mediante la institución del "bien de familia", y a la consecuente declaración de inembargabilidad e inalienabilidad de ciertos bienes, como la vivienda familiar y el ajuar doméstico ${ }^{17}$.

No obstante el cambio radical (resultado en algunos casos de una verdadera revolución) ${ }^{18}$ propuesto por esta nueva generación de Constituciones en materia de derechos económicos, sociales y culturales, en general, y sobre la familia, en particular, lo cierto es que el carácter meramente programático de la mayoría de sus disposiciones sirvió de excusa (a un aparato judicial asociado aún, en muchos casos, al proyecto liberal-conservador de la generación precedente) para postergar por largos años su efectiva aplicación; llegándose incluso, en algunas ocasiones, a su desmantelamiento o, en el mejor de los casos, minimización luego del derrocamiento de los regímenes políticos que habían promovido su sanción ${ }^{19}$.

En realidad hubo que esperar hasta los años ochenta del siglo xx, con la caída de las dictaduras cívico-militares que asolaron la mayor parte de los países de Latinoamérica (con las únicas excepciones de Colombia, Costa Rica, México y Venezuela) en la década anterior, mediante la implantación de un terrorismo de Estado bajo el cual los derechos fundamentales fueron vulnerados en forma

I4 Cfr., p. ej., la CCub/ı 940, art. 43; la CBol/ı945, art. I3 I; la CHon/ı 957, art. ro .

i 5 Cfr., p. ej., los arts. i8 i de la CSal/ı 950; ro de la CHon/ı957 y i97 de la CBol/ı967.

I6 Entre las que podemos citar, a mero título ejemplificativo, la particular atención prestada a la familia numerosa (cfr., p. ej., los arts. 40[2] de la CUru/ı934, I33 de la CBol/ı945, ı64 de la CBra/I946), a las asignaciones familiares (cfr., p. ej., los arts. i 85 [2.c] de la CEcu/ I 946, I 27 [r] de la CHon/ı957, 94 de la CVen/ı96ı, I58[2] de la CBol/ı967, io5 de la CPar/ı967) y a la protección de la maternidad (cfr., p. ej., los arts. 5 I de la CPer/r933, 4I[2] de la CUru/r934, i 97 de la CHon/ı 936, 6o de la CSal/ı 939, 43[r] de la CCub/ı940, I3 I de la CBol/ı 945, i64 de la CBra/ı 946, r62 [ı] de la CEcu/ı 946, 37.II.4 de la CArg/ı949, 74 de la CVen/ı 96 I, 85 de la CPar/ig67).

i 7 Cfr., p. ej., la CMéx/ı 9ı 7, art. i 23.xxvin; la CUru/ı934, art. 48; la CBol/ı938, art. I33; la CSal/ı 939, art. 6ı ; la CEcu/ı 946, art. i 66; la CArg/ı 949, art. 37.II.3; la CArg/ı 853-ı 957, art. ı4bis; la CHon/ı 957, art. Io9; la CVen/ı96 I, art. 73; la CPar/ı967, art. 82

i 8 Piénsese, p. ej., en la Revolución mexicana de i 9 ıо (cuyo culmen se alcanza con la CMéx/ı 9I 7), en la Revolução brasileña de I930, con la cual accedió al poder Getúlio Vargas (a quien se debe, primero, la CBra/ı934 y, luego, la CBra/ı938), o en la denominada "Revolución del 43", que abrió las puertas en Argentina al gobierno "justicialista” de Juan D. Perón (que promovió la CArg/r949).

I9 Paradigmático en este sentido fue el caso de Argentina, donde la Constitución liberal-conservadora de 1853 fuera sustituida por la denominada Constitución "justicialista" de i 949 que reconoció -ampliamente- los "Derechos del trabajador, de la familia, de la ancianidad y de la educación y la cultura”; y la cual a su vez, luego de la destitución en i955 de Juan D. Perón, fue reemplazada por el texto constitucional precedente, al que se agregó en I 957 el art. I4 bis donde se incorporaron -aunque menos detalladamente- los denominados "Derechos sociales" (cfr., una vez más, SAGǗ́s, ob. cit., pp. 2 I 7 s.). 
sistemática, para que se asistiera en la Región a un renacimiento del constitucionalismo, acompañado de una especial consideración de la teoría de los derechos humanos, lo que se vio reflejado en una democratización de la vida nacional en todos sus aspectos (político, social, cultural, etc) e, incluso, en la adopción de mecanismos de participación ciudadana complementarios de las instituciones propias de la democracia representativa (tales como el referéndum, el plebiscito, la iniciativa popular, la revocación del mandato, la consulta previa, etc) ${ }^{20}$.

Desde esta particular perspectiva y con la finalidad de suplir las falencias del constitucionalismo social - pero sin romper con sus postulados-, esta "segunda oleada" del reformismo constitucional latinoamericano ${ }^{21}$ se propuso convertir el "Estado 'legislativo' de derecho" (o "Estado Legal") en un "Estado 'constitucional' de derecho" (o "Estado Constitucional”), concibiendo la Constitución (cuyo texto se integra además, en algunos casos, con los tratados sobre derechos humanos, a los que se les otorga jerarquía constitucional mediante el empleo de diferentes expedientes ${ }^{22}$ ) como un mandato directo del poder constituyente al

20 Sobre este último particular remitimos, entre otros, a Jesús Orozco Henríquez, "Nuevas tendencias sobre sistema electoral, sistema de partidos y mecanismos de democracia directa en América Latina”, en Carbonell, Carpizo y Zovatto (coords.), Tendencias del constitucionalismo en Iberoamérica, cit., pp. 227 ss., y a Roberto GARgarella, "El constitucionalismo latinoamericano y la "sala de máquinas" de la Constitución (ı980-20го)", en Gaceta Constitucional, n. ${ }^{\circ} 48$, Lima, 20 I I, pp. 289 ss., quien nos ilustra también las dificultades que se han presentado para la efectiva implementación de estos mecanismos.

2 I Cfr., asimismo, sobre esta otra expresión Gargarella y CourTis, ob. cit., p. 25.

22 Entre los que se pueden distinguir, a mero título ejemplificativo, la introducción de cláusulas que: i) disponen (inspiradas en el art. I0.2 CEsp/I 978) que los derechos reconocidos constitucionalmente deben ser interpretados de conformidad con los tratados internacionales sobre derechos humanos (cfr., p. ej., la CCol/I 99 I, art. 93 [2] ; la CPer/ı 993, $4 .{ }^{\text {a }}$ disp. final; la CBol/2009, arts. I 3.IV y 256 .II; la CRD/20IO, art. 74.4; la CMéx/I 9I 7-20 I I, art. I [2]); ii) reconocen como implícitos en los textos constitucionales los derechos que se deducen de los tratados internacionales sobre derechos humanos o que sean inherentes a la persona humana, con igual valor y jerarquía que los enumerados expresamente en ellos (cfr., p. ej., la CUru/I967, art. 72; la CHon/ı 982, art. 63; la CBra/ı 988, art. 5.LxxviII.2; la CCol/ı99 I, art. 94; la CPar/ı 992, art. 45; la CGua/ı 993, art. 44; la CPer/ı 993, art. 3; la CEcu/ı 998, art. I 9; la CVen/ı 999, art. 2 2; la $\mathrm{CEcu} / 2008$, art. I I.7); iii) contienen referencias a los tratados sobre derechos humanos como "normas-principios" (cfr., p. ej., la CCh/ı98 I-ı 989, art. 5; la CBra/ı988, arts. I.III y 4.II; la CCol/I99I, arts. 93 y 2 I 4.2; la CPar/I992, arts. I42 y I45; la CArg/I 853-I 994, art. 75.24; la CGua/ı 996, art. I 49; la CEcu/ı 998, art. 23; la CVen/ı 999, Preámbulo; la CEcu/2008, arts. ıо, 4I , 57, 58, 93, I 56, I 7 I , I 72, 384, 398, 4I 6.7; la CBol/2009, art. I4.III; la CMéx/I 9 I 7-20 I I, art. I [ry3]); o iv) otorgan expresamente jerarquía constitucional a ciertos tratados sobre derechos humanos (cfr., p. ej., la CPer/ı 979, art. I05; la ccr/ı 949-ı989, art. 48; la CArg/I853-I994, art. 75.2 2; la CGua/I 993, art. 46; la CNic/r 986-ı 995, arts. 46 y 7 I; la CEcu/ı 998, arts. I 7 y i 8; la CVen/ı 999, arts. 23 y 78; la CEcu/2008, art. 424; la CBol/2009, art. 256.I; la CrD/20Io, art. 74.3). Por último cabe señalar que, en algunos casos, la referida jerarquía de los tratados sobre derecho humanos ha sido deducida por la respectiva jurisprudencia nacional de la interpretación de algunas disposiciones constitucionales (tal como sucediera, p. ej., con los arts.

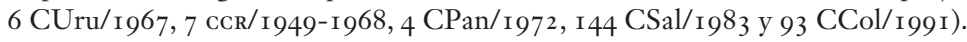

Sobre esta materia cfr., entre otros, Ariel E. Dulitzky, "Los Tratados de Derechos Humanos en el constitucionalismo iberoamericano", en Thomas Buergenthal y Antonio A. Cançado 
poder constituido (o poder legal), cuya resultante es la "constitucionalización" (y, en su caso, también la "internacionalización”) del ordenamiento jurídico, la que opera tanto en el plano interpretativo como aplicativo ${ }^{23}$. Como consecuencia de este proceso, el simple "principio de legalidad" (según el cual una norma jurídica es válida no por ser justa sino por haber sido emanada por una autoridad con competencia normativa) resulta superado por el "principio de supremacía de la Constitución” (el cual se integra además, respecto de los instrumentos internacionales, con el "principio de supremacía de la Convención")²4.

Con este cambio de paradigma se busca garantizar la aplicación efectiva de los derechos fundamentales reconocidos por las Cartas constitucionales estatales y por los tratados internacionales en una triple dirección: i) abarcando todo tipo de derechos (es decir, tanto los derechos de libertad como los derechos económicos, sociales y culturales, e incluso los nuevos derechos al ambiente, a la información, a la defensa de los consumidores, de las minorías, etc., recientemente constitucionalizados); ii) frente a todos los poderes (o sea, no solo con relación a los poderes públicos sino también respecto de los privados), y iii) a todos los niveles (esto es, tanto en el derecho estatal como en el internacional) ${ }^{25}$. Para poder alcanzar estos objetivos se parte de la base de que las normas consti-

Trindade (comps.), Estudios especializados de Derechos Humanos, vol. I, San José de Costa Rica, I996, pp. I 29 ss.; ID., "La aplicación de los Tratados sobre Derechos Humanos por los tribunales locales: un estudio comparado", en Martín Abregú y Christian Courtis, La aplicación de los Tratados sobre Derechos Humanos por los tribunales locales, Buenos Aires, I997, pp. 33 ss.; Susana Castañeda Otsu, "El principio de interpretación conforme a los Tratados de Derechos Humanos y su importancia en la defensa de los derechos consagrados en la Constitución”, en Ricardo Méndez Silva (coord.), Derecho internacional de los Derechos Humanos. Memoria del VII Congreso iberoamericano de Derecho constitucional, México, D.F., 2002, pp. 2 I I ss.; Héctor FIXZamudio, "El Derecho internacional de los Derechos Humanos en las Constituciones latinoamericanas y en la Corte Interamericana de Derechos Humanos", en Revista Latinoamericana de Derecho, México, D.F., enero-junio 2004, pp. I4I ss.; Allan R. Brewer-Carías, "La aplicación de los Tratados internacionales sobre Derechos Humanos en el orden interno de los países de América Latina", Revista del Instituto Interamericano de Derechos Humanos, vol. 46, San José de Costa Rica, 2007, pp. 2 I 9 ss., y Marco Gerardo Monroy Cabra, "El Derecho internacional como fuente del Derecho constitucional", Anuario Colombiano de Derecho Internacional, n. ${ }^{\circ}$ I, Bogotá, 2008, pp. I07 ss.

23 Cfr., entre otros, Roberto Viciano Pastor y Rubén Martínez Dalmau, "Fundamentos teóricos y prácticos del nuevo constitucionalismo latinoamericano", en Gaceta Constitucional, n. ${ }^{\circ}$ 48, Lima, 20 I I, pp. 309 ss., quienes destacan que el artículo i de la CEcu/2008 hace expresamente referencia a este cambio de orientación al disponer que "El Ecuador es un Estado Constitucional de Derechos y Justicia”.

24 Cfr., sobre este particular, Luigi Ferrajoli, "Pasado y futuro del Estado de derecho", Revista Internacional de Filosofía Política, uned-unam, n. ${ }^{\circ}$ I 7 , Madrid-México, D.F., 200 I, pp. 3 I ss.

25 Así se expresa, también, Luigi Ferrajoli, "Sobre los derechos fundamentales”, en Carbonell, Miguel (ed.), Teoría del neoconstitucionalismo, Madrid, 2007, pp. 72 s., quien concluye su discurso afirmando que "El futuro del constitucionalismo jurídico, y con él de la democracia, está [...] confiado a esta triple articulación y evolución: hacia un constitucionalismo social, junto al liberal; hacia un constitucionalismo de derecho privado, junto al de derecho público; hacia un constitucionalismo internacional, junto al estatal". 
tucionales (y, en algunos casos, las de los tratados internacionales) son idóneas para reglamentar directamente no solo la organización del Estado y las relaciones entre este y los ciudadanos, sino también las relaciones de los particulares entre sí (Drittwirkung) ${ }^{26}$, y para ser aplicadas de manera inmediata y directa ${ }^{27}$ tanto por los tribunales (sean estos constitucionales u ordinarios) como por los demás órganos del Estado ${ }^{28}$.

Ahora bien, aunque este neoconstitucionalismo se ha desarrollado también en otras latitudes (p. ej., la Europa occidental de posguerra, el África poscolonial y la Europa oriental postsoviética), fue sin embargo en América Latina donde esta nueva orientación adquirió ribetes particulares, a tal punto que desde hace ya algunos años se ha comenzado a hablar con cierta vehemencia de un "nuevo constitucionalismo latinoamericano", cuyas características más salientes -en lo que aquí interesa- son: i) el cambio de la identidad axiológica de las Constituciones de la Región, cuyos textos fueron reformados en su gran mayoría, ya sea sustituyéndolos in toto ${ }^{29}$ o modificándolos solo de manera parcial pero mudando su sustancia3; ii) el abundante catálogo de derechos que las Constituciones

26 Cfr., entre otros, Iván Escobar Fornos, "Aplicación de los derechos fundamentales en las relaciones privadas", en Carbonell, Carpizo y Zovatto (coords.), Tendencias del constitucionalismo en Iberoamérica, cit., pp. I 5 I ss.

27 Tal como se desprendería, expresa o implícitamente, de los artículos 5.LXxviII. I de la CBra/ı 98 , 45i.f de la CPar/ı992, i 8[ry3] de la CEcu/ı998, z i.f de la CVen/ı999, i r.3 y 426 de la CEcu/2008 y $74 \cdot 3$ de la CRD/20IO.

En esta misma línea resulta emblemático lo dispuesto por el nuevo Código civil y comercial argentino de $20 \mathrm{I} 4$ en los artículos I, sobre las "Fuentes y aplicación” del derecho ("Los casos que este Código rige deben ser resueltos según las leyes que resulten aplicables, conforme con la Constitución Nacional y los tratados de derechos humanos en los que la República sea parte..."), y 2, sobre la "Interpretación” e integración ("La ley debe ser interpretada teniendo en cuenta sus palabras, sus finalidades, las leyes análogas, las disposiciones que surgen de los tratados sobre derechos humanos, los principios y valores jurídicos, de modo coherente con todo el ordenamiento").

28 Cfr., en este sentido, Riccardo Guastini, "Sobre el concepto de Constitución”, en Carbonell (ed.), Teoría del neoconstitucionalismo, cit., pp. 23 ss.

29 P. ej., la CPer/ı 979, la CHon/ı 982 , la CSal/ı 983 , la CGua/ı 985 , la CNic/ı 986, la CBra/ı 988 , la CCol/ı 99 I, la CPar/ı 992, la CBol/ı 995, la CRD/ı 994, la CEcu/ı 998, la CVen/ı 999. Incluso, en ciertos casos, se ha producido ya la sustitución de algunos de estos textos constitucionales (tal como ha sucedido con la CPer/ı 979, reemplazada por la CPer/ı 993; la CGua/ı 985, por la CGua/ı 993; la CRD/I 994, por la crD/20 Io; la CBol/ı 995, por la CBol/2009, y la CEcu/ı 998 , por la CEcu/2008).

30 P. ej., la CCh/ı 98 I-ı 989, la ccr/ı 949-ı 989, la CMéx/ı 9 I 7-ı 992-20 i i, la CArg/ı 853-ı 994. Consideramos que la primera Constitución de este grupo fue la de Perú de i979, cuyo artículo I05 dispuso que los preceptos contenidos en los tratados relativos a los derechos humanos tenían jerarquía constitucional y que no podían ser modificados sino por el procedimiento que regía la reforma de la Constitución. Sin embargo esta opinión no es unánime. Así, para algunos, ese primado correspondería a las Constituciones de Guatemala de i 985 y de Brasil de i 988 (cfr. Héctor Fix-Zamudio, "Algunas tendencias predominantes en el Constitucionalismo latinoamericano contemporáneo", en Ricardo Combellas [coord.], El nuevo Derecho Constitucional latinoamericano, vol. I, Caracas, I996, p. 46); no faltando incluso quienes afirmen que, 
latinoamericanas reconocen, tanto individuales (de las personas) como colectivos (de las comunidades, pueblos, nacionalidades o grupos), e incluso, últimamente, a favor de la misma naturaleza (la Pacha Mama) ${ }^{3}$, el cual se ve ampliado además por el reenvío que las mismas hacen a los textos de los instrumentos internacionales sobre derecho humanos y por la consecuente aplicación de los principios de progresividad ${ }^{32}$ y de interpretación pro bomine 33 (que incluso en algunas Constituciones latinoamericanas deviene pro bomine et natura34); y iii) la preocupación por lograr la máxima efectividad de los derechos reconocidos, completando sus regulaciones con la introducción de instrumentos de protección jurídica reforzada de los mismos (tales como el amparo, el habeas corpus, el habeas data, las acciones populares y de grupo, etc) y con la progresiva puesta en marcha, por la mayor parte de los textos constitucionales latinoamericanos, de un mecanismo de control concentrado de constitucionalidad (en manos de una Corte o de un Tribunal constitucional, o bien de una Sala constitucional del Tribunal Supremo $\left.{ }^{35}\right)^{36}$.

en realidad, "el nuevo constitucionalismo latinoamericano no tiene una identidad temporal" precisa (así se expresan, p. ej., Viciano Pastor y Martínez Dalmau, ob. cit., p. 3 I9).

3 I Con relación a esta última categoría de derechos, el caso paradigmático está representado por la CEcu/2008, que le dedica al tema todo el Capítulo séptimo (arts. 7 I-74), sobre lo cual remitimos a EduARDo Gudynas, "La ecología política del giro biocéntrico en la nueva Constitución de Ecuador", Revista de Estudios Sociales, n.32, Bogotá, abril de 2009, pp. 34 ss.

32 Este principio está reconocido expresamente, en el derecho internacional, por el Pacto Internacional de Derechos Económicos, Sociales y Culturales de 1966 (art. 2.I) y por la Convención Americana sobre Derechos Humanos de I 969 (arts. 26, 4r.b y 77.I), y en el constitucionalismo latinoamericano, por la CVen/r 999 (art. I9), la CEcu/2008 (art. 423.3) y la CMéx/I91 7-20 I I (art. I[3]). (Acerca de este principio hermenéutico cfr., entre otros, Brewer-Carías, ob. cit., pp. 268 ss.).

33 Este otro principio ha sido también reconocido, en el derecho internacional, por el Pacto Internacional de Derechos Civiles y Políticos de ig66 (art. 5) y por la Convención Americana sobre Derechos Humanos de I969 (art. 29), y en el derecho constitucional latinoamericano, por la CEcu/1998 (art. I8[2]), la CEcu/2008 (arts. ir.5 y 427) y, más claramente, por la CMéx/r9i 7-20I I (art. I[2]). (Sobre este principio interpretativo puede consultarse con provecho a Mónica PINTO, "El principio pro homine. Criterio hermenéutico y pauta para la regulación de los Derechos humanos", en Aa.vv., La aplicación de los Tratados sobre Derechos Humanos, Buenos Aires, I997, pp. I63 ss.).

34 Así se expresa, con referencia a la CEcu/2008 y a la CBol/2009, Alejandro Medici, "Teoría constitucional y giro decolonial: narrativas y simbolismo de la Constitución. Reflexiones a propósito de la experiencia de Bolivia y Ecuador", Gaceta Constitucional, n . 48, Lima, 20 I , p. 34I.

35 Sobre este particular cfr., en general, Francisco J. Eguiguren Praeli, Los tribunales constitucionales en Latinoamérica: una visión comparativa, Buenos Aires, 2000, passim; Eduardo Ferrer Mac-Gregor, Los tribunales constitucionales iberoamericanos, México, D.F., 2002, pp. 65 ss.; Domingo García Belaunde, "Los tribunales constitucionales en América Latina", Revista de Derecho Político, n. ${ }^{\circ}$ 6i, Lima, 2004, pp. 309 ss.; y Gretchen Helmke y Julio Ríos Figueroa (coords.), Tribunales constitucionales en América Latina, México, D.F., 2010 , passim.

${ }_{3} 6$ Sobre estos caracteres (que no son ni exclusivos ni excluyentes) cfr. nuevamente, entre otros, 
Con motivo de la "inflación" de derechos reconocidos y de las dificultades que podrían presentarse en la práctica para su efectiva realización, esta tercera generación de Constituciones latinoamericanas ha sido objeto de críticas ${ }^{37}$, las que sin embargo -en muchos casos- se han revelado exageradas, pues lejos de constituir los referidos textos constitucionales una manifestación -en el ámbito jurídico- del denominado "realismo mágico latinoamericano", los mismos han permitido dar por vez primera una respuesta eficaz y concreta a las reivindicaciones de los sectores más vulnerables e históricamente marginados de la sociedad latinoamericana (como son los grupos indígenas o de origen africano, las minorías sexuales, las mujeres y los niños, las personas con capacidad diferentes, los adultos mayores, etc) ${ }^{38}$.

Es por ello que consideramos que una de las consecuencias más relevantes de este cambio de paradigna -que tanta importancia adquiere en el tema que nos ocupa- está representada por los límites jurídicos impuestos por la noción misma de los derechos fundamentales en protección de las minorías, en atención a que, si bien la democracia funciona sobre la base del respeto de las decisiones mayoritarias, no debe perderse de vista que la misma consiste en "el gobierno de la mayoría respetuoso de los derechos de la minoría”, y no en la "dictadura" de la primera (cuya voluntad podría traducirse, incluso, en decisiones inconstitucionales por ser contraria a los principios y valores del "bloque de constitucionalidad") 39 .

En efecto, en una sociedad pluralista como la contemporánea la voluntad de la mayoría expresada en una ley no significa necesariamente que todo lo que se opone a ella sea antijurídico, ya que la misma puede y debe convivir también con el legítimo disenso de quienes no comparten la opinión mayoritaria y cuya represión sería discriminatoria. Desde este punto de vista los derechos fundamentales (reconocidos por las Constituciones y por los tratados internacionales sobre derechos humanos) aparecen como excepciones a la regla de la mayoría en aquellos temas en los que no existen verdades irrefutables $4^{40}$, debiéndose sustituir

Gargarella y Courtis, ob. cit., pp. 3i s. y Viciano Pastor y Martínez Dalmau, ob. cit., pp. 3 I 7 ss.

Así, a mero título ejemplificativo, cfr. Alberto Pérez Calvo, "Características del nuevo constitucionalismo latinoamericano”, en Claudia Storini y José Alenza García (eds.), Materiales sobre neoconstitucionalismo y nuevo constitucionalismo latinoamericano, Pamplona, $20 \mathrm{I} 2$, pp. 32 ss., quien se ocupa principalmente del análisis de la CVen/ı999, la CEcu/2008 y la CBol/2009.

38 Por el contrario, la austeridad de algunos textos constitucionales (cfr., p. ej., la CCh/r98I) ha servido de excusa, durante mucho tiempo, para retardar una tutela amplia y efectiva de los derechos fundamentales (como destacan Gargarella y Courtis, ob. cit., p. 32).

39 Cfr., en este sentido, Werner Goldschmidt, Introducción filosófica al derecho. La teoría trialista del mundo jurídico y sus horizontes, Buenos Aires, $1983^{6}$, p. I.

40 En atención a que, como bien señala Ferrajoli, ob. cit., 86, "los derechos fundamentales son siempre leyes del más débil contra la ley del más fuerte". 
por tanto en estos casos la decisión mayoritaria por el consenso elaborado con base en un diálogo diversificado ${ }^{4}$.

\section{B. La "constitucionalización" e "internacionalización" del derecho de familia}

El proceso que acabamos de describir ha tenido un fuerte impacto en el derecho de familia, ya que al imponerse la "relectura" 42 de sus disposiciones a la luz de los textos constitucionales y de los instrumentos internacionales sobre derechos humanos, esta nueva metodología de interpretación y aplicación del derecho terminó por influir profundamente sobre la regulación de las relaciones familiares 43 ; esto por cuanto una sociedad democrática-caracterizada por el pluralismo, la tolerancia y el espíritu de apertura- supone el reconocimiento de una familia democrática y pluralista, y en consecuencia una reconsideración de la institución familiar desde esta nueva perspectiva 44.

4I En este sentido cfr., entre otros, Ricardo L. Lorenzetti, Teoría de la decisión judicial. Fudamentos de derecho, Santa Fe-Buenos Aires, 2008, pp. 4I 7 ss.

42 Parafraseamos aquí al jurista italiano Rescigno, Pietro, "Per una rilettura del codice civile", en Giurisprudenza Italiana, Roma, I968, Parte Iv, c. 209 ss.

43 Cfr., entre otros, Aída Kemelmajer de Carlucci, "El Derecho de Familia en la República Argentina en los inicios del siglo xxI. Su inexorable proceso de constitucionalización y de adecuación a los Tratados internacionales de Derechos Humanos", en Revista de Derecho Comparado, n. ${ }^{\circ}$ Io (Derecho de Familia II), Buenos Aires-Santa Fe, 2005, pp. 8 ss., e Íd., "Las nuevas realidades familiares en el Proyecto de Código civil y comercial argentino", en Aída Kemelmajer De Carlucci, Daniel Ángel Borrillo y Jesús Flores Rodríguez (coords.), Nuevos desafíos del Derecho de Familia, 2014, pp. 99 ss.: si bien la autora analiza los cambios operados en esta materia en el derecho argentino, sus consideraciones son extensibles también a los ordenamientos de los demás países latinoamericanos.

44 Sobre este particular resultan paradigmáticas las consideraciones de la sentencia del Superior Tribunal de Justicia brasileño del 25/ro/20 I (cfr. infra nota 86) por la que se reconoció a las parejas del mismo género el derecho a contraer matrimonio en atención a que "não obstante a omissão legislativa sobre o tema, a maioria, mediante seus representantes eleitos, não poderia mesmo 'democraticamente' decretar a perda de direitos civis da minoria pela qual eventualmente nutre alguma aversão. Nesse cenário, em regra é o Poder fudiciário - e não o Legislativo- que exerce um papel contramajoritário e protetivo de especialíssima importância, exatamente por não ser compromissado com as maiorias votantes, mas apenas com a lei e com a Constituição, sempre em vista a proteção dos direitos bumanos fundamentais, sejam eles das minorias, sejam das maiorias. Dessa forma, ao contrário do que pensam os críticos, a democracia se fortalece, porquanto esta se reafirma como forma de governo, não das maiorias ocasionais, mas de todos", de tal manera que se concluye que "enquanto o Congresso Nacional, no caso brasileiro, não assume, explicitamente, sua coparticipação nesse processo constitucional de defesa e proteção dos socialmente vulneráveis, não pode o Poder Fudiciário demitir-se desse mister, sob pena de aceitação tácita de um Estado que somente é 'democrático' formalmente, sem que tal predicativo resista a uma mínima investigação acerca da universalização dos direitos civis" (cfr. <http://www. mpsp.mp.br/portal/page/portal/Civel_Geral/Registros_Publicos/Jurisprudencia_registros/ sTJ-\% 20REsp\% 20 I I 83378 -casamento\% 2 ohomoafetivo.pdf>, n ${ }^{\circ} .9$ y Io, pp. 7 s. [consultado el 24/07/2015]). 
Así, respecto de la "constitucionalización” de la regulación de las relaciones familiares, la mayor parte de los textos constitucionales pertenecientes a la "segunda oleada" del reformismo constitucional latinoamericano se ha preocupado también por reglar especialmente la familia, continuando con la tendencia inaugurada en esta materia por el constitucionalismo social (cfr. supra I.A) y en algunos casos incluso intentando profundizarla ${ }^{45}$, aunque sin obtener en todos los casos -como veremos más adelante- los resultados innovadores que el neoconstitucionalismo latinoamericano ha sabido conseguir en otros ámbitos del derecho.

Sin perjuicio de ello, cabe señalar que todas las Constituciones latinoamericanas vigentes reafirman -expresa o implícitamente- el rol de la institución familiar como "base", "núcleo" o "elemento fundamental de la sociedad"46, ya sea que luego hayan optado para su regulación por una metodología más sistemática y/o "maximalista" 47 o bien por una menos sistemática y/o "minimalista", y que a más de ello sus disposiciones se complementan con el reenvío que las mismas hacen a los instrumentos internacionales que integran el "bloque de constitucionalidad" 48 .

Empero, como también tendremos oportunidad de comprobar a continuación, esta diferente metodología adoptada por el constituyente para normar la familia no prejuzga sobre la mayor o menor apertura del respectivo ordenamiento constitucional a las profundas transformaciones que se han operado en las últimas décadas en el ámbito de las relaciones familiares. En efecto, si bien

Preocupándose, entre otras cosas, por la protección contra la violencia intrafamiliar (cfr., p. ej., CCol/r 99 I, arts. 42 [3] y 44; CPar/I 992 , arts. 54 y 6o; CEcu/2008, arts. 35, 36, 38.4, 66.3.b, 8I ; CBol/2009, arts. I 5.II y III, 6 I.I, 68.II; CBra/I988-20IO, arts. 226.8, 22 ; CRD/20IO, art. 42.2) y de género (cfr., p. ej., CEcu/2008, art. 33 I; CBol/2009, art. I 5.II y III; CRD/20IO, art. 42.2).

46 A la cual incluso algunas de ellas llegan a considerar directamente como sujeto de derechos (cfr., p. ej., ccr/I949, art. 5 I; CMéx/ı91 7-ı980, art. 4; CNic/ı986, art. 70; CPer/ı 993, art. 6). Es por ello que Pierangelo Catalano, Diritto e persone, Torino, i99o, pp. I io ss., e iD., "Sistema y ordenamientos: el ejemplo de América Latina", en Roma e America. Diritto romano comune, vol. i 8, Módena-Bogotá, 2004, pp. 30 ss. (<www.romaeamerica.it>), ha llegado a afirmar, con acierto, que en el Subsistema jurídico latinoamericano (en cuanto desarrollo interno propio del Sistema jurídico romanístico) la "unidad social" es la familia y no el individuo aislado) (como sucede en otras experiencias jurídicas, tales como la del common law) (cfr. infra Conclusiones).

47 Cfr., p. ej., CCub/I976, arts. 35-38; CHon/ı 982, arts. I I I-I I6; CSal/I983, art. 32-36; CNic/ı 986, arts. 70-79; CBra/ı 988, arts. 226-230; CCol/ı99ı, arts. 42-46; CPan/ı 992, arts. 56-62; CPar/ı 992, arts. 49-6 г; CGua/ı 993, arts. 47-54; CPer/ı 993, arts. 4-6; CVen/ı 999, arts. 75-8r; CEcu/2008, arts. 67-69; la CBol/2009, arts. 62-66; CRD/20Io, arts. 55-58.

48 Cfr., p. ej., CR/I949-I989, arts. I 8 y 5I-53; CArg/I853-I957-I994, arts. I4bis, 20, 75.19 y 75.22; CUru/I967, arts. 40-49; CMéx/I 9I 7-I974-I980-I983-I992-2000-20I I, arts. I, 2,4 y I 23.XXVIII; CCh/I 98 I-I989, arts I [2y5], 4 y 5. Sobre este particular cfr., en general, RicARDo Lorenzetti, Las normas fundamentales de Derecho privado, Buenos Aires-Santa Fe, i 995, pp. 204 ss., y, en especial, Yanira Zúñiga y Susan Túner, "Sistematización comparativa de la regulación de la familia en las constituciones latinoamericanas", Revista de Derecho, Universidad Católica del Norte, año 20, n. ${ }^{\circ}$ 2, Coquimbo, 2013 , pp. 269 ss. 
el ingreso a la Constitución de normas sobre la institución familiar sirve para disipar toda duda acerca de la posibilidad de invocarlas para la interpretación e integración del ordenamiento jurídico, o directamente para la descalificación de una norma inferior que sea incompatible con las mismas 49 , el excesivo detallismo que caracteriza a algunas Constituciones latinoamericanas puede revelarse en la práctica contraproducente al impedir o dificultar la adaptación de sus disposiciones a los cambios sociales. Por el contrario, la escasa regulación contenida en otros textos constitucionales, que in primis parecería una desventaja, en realidad no lo es, y ello por cuanto, al integrarse sus disposiciones con el derecho internacional, cuando se deba regular esta materia solo se lo podrá hacer ajustando la legislación secundaria a los estándares internacionales (so pena de incurrir en responsabilidad por violación de las convenciones sobre derechos humanos $)^{5 \circ}$.

Son varios los instrumentos internacionales sobre derechos humanos, receptados por las Cartas constitucionales de América Latina y/o a los cuales ellas reenvían, que se ocupan de la protección de las relaciones familiares (tanto en sus aspectos generales como particulares) ${ }^{5}$. Entre ellos cabe señalar la Declaración Universal de los Derechos Humanos de I 948 (arts. I 6 y 25.2), la Declaración Americana de los Derechos y Deberes del Hombre de i 948 (arts. 6, 7 y 30), el Pacto Internacional de Derechos Económicos, Sociales y Culturales de i 966 (art. Io), el Pacto Internacional de Derechos Civiles y Políticos de i 966 (arts. 23 y 24) y la Convención Americana sobre Derechos Humanos de r969 (arts. I 7, I 9 y 27), cuyos textos reconocen de manera uniforme: i) la protección de la familia por parte de la sociedad y del Estado, en cuanto elemento natural y fundamental de la sociedad, la cual no puede ser suspendida ni siquiera en caso de guerra, peligro público u otra emergencia similar; ii) el derecho de constituir una familia, sin otra restricción que la edad mínima y demás condiciones requeridas por la ley, siempre que estas no afecten al principio de no discriminación; iii) la igualdad de derechos y de responsabilidades del hombre y de la mujer en el ámbito de la familia; iv) el derecho de contraer matrimonio con el libre

49 Tal como lo manifestara Germán Bidart Campos, "El derecho de familia desde el derecho de la Constitución", Revista "Entre abogados", Foro de Abogados de San Juan, año Iv, n. ${ }^{\circ}$ 2, San Juan (Argentina), I998, p. I 7 .

50 Cfr. en este sentido, p. ej., el artículo 32 de la Convención de Viena sobre el Derecho de los Tratados de r 969 y, en el Sistema interamericano, el artículo 2 de la Convención Americana sobre Derechos Humanos de r 969 (cfr. nuevamente, en este otro sentido, Lorenzetti, Las normas fundamentales de derecho privado, cit., pp. 207 ss).

5 I Ese reenvío puede ser efectuado al derecho internacional convencional en general (cfr., p. еj., CBra/ı 988, art. 5.3; CCh/ı98 I-ı 989, art. 5; cCR/ı949-ı989, art. 48; CCol/ı 99ı, art. 93; CPar/I992, art. I42; CNic/I993, art. 46; CPer/ı993, $4 .^{\text {a }}$ disp. final; Ven/I999, arts. 22 y 23 ; CEcu/2008, arts. I I.3 y 7, 4I, 57, 58, I 56, I 72, 384, 398, 4I 6.7, 4I 7, 424, 426, 428 у 436. I; CBol/2009, arts. I3.IV, I4.III, 256.I, 4Io.I; CRD/20I0, art. 74.3; CMéx/I9I 7-201 I, art. I[2]) o a algunos de los tratados específicos que se indican a continuación en el texto (cfr., p. ej., CArg/I 853-I 994, art. 75.22; CNic/I986-I995, arts. 46 y 7 I). 
y pleno consentimiento de los contrayentes, los que asimismo deben disfrutar de iguales derechos para su celebración y su disolución; v) la protección de la maternidad y de la infancia; y vi) la igualdad de derechos entre los hijos nacidos dentro y fuera del matrimonio.

Muchos de estos derechos han sido reafirmados luego por la "Convención sobre la eliminación de todas las formas de discriminación contra la mujer" de 1979 (arts. 5.b y i6) y la Convención sobre los Derechos del Niño de I 989 (arts. 3, 5, 7, 9, Іо, I 8, 20 у 2 I), las que además -respectivamente y en lo que a nosotros aquí interesa- han agregado: i) la obligación de los Estados de garantizar la igualdad "real" entre los cónyuges, eliminando la figura de la "potestad marital" y toda otra forma de discriminación contra la mujer en el ámbito de las relaciones familiares ${ }^{52}$; y ii) la referencia al "interés superior del niño" 53 , como parámetro primordial a tener en cuenta en todas las medidas concernientes a los niños y que tomen las instituciones públicas y privadas de bienestar social, los tribunales, las autoridades administrativas y los órganos legislativos ${ }^{54}$. A estos instrumentos internacionales, que regulan algunos aspectos particulares de las relaciones de familia, debe añadirse también el Convenio n. ${ }^{\circ}$ i69 de la Organización Internacional del Trabajo sobre Pueblos Indígenas y Tribales en Países Independientes de I989, en razón de la incidencia que el mismo tiene sobre la tutela "multicultural" de la familia, en particular sobre la denominada "familia indígena" (cfr. infra II.G) 55 .

52 Asegurando, de este modo, condiciones de igualdad absoluta entre hombres y mujeres en lo concerniente a: i) los derechos y responsabilidades como progenitores, cualquiera que sea su estado civil; ii) los derechos sexuales y reproductivos; iii) los derechos y responsabilidades respecto de la tutela, la curatela, la custodia y la adopción; iv) el derecho de elegir el apellido, la profesión y la ocupación; y v) los derechos relativos a la propiedad, a la gestión, a la administración, al goce y a la disposición de bienes.

53 Algunas Cartas constitucionales latinoamericanas ya han incorporado también esta referencia, bien directa y expresamente en sus textos (cfr., p. ej., CVen/ı999, arts. 75[2] y 78; CEcu/20o8, art. 44; CBol/2009, arts. 59.II, 60, 65; CRD/2010, art. 56; CMéx/I9I 7-20I I, arts. 4[8], I8[5] y 73.xxix.P), bien por remisión al texto de la Convención sobre los Derechos del Niño, a la que otorgan rango constitucional (cfr. CCol/ı 99 I, art. 44[гі.f]; CArg/ı 853-I 994, art. 75.22; CNic/r986-r995, art. 7I). (El antecedente más remoto de estas disposiciones lo constituye, una vez más, la CEsp/r93 I, cuyo art. 43[6] disponía que "El Estado prestará asistencia [...] a la infancia, haciendo suya la 'Declaración de Ginebra' o tabla de los derechos del niño” de I 924 ).

$54 \mathrm{Al}$ respecto el Comité de los Derechos del Niño ha precisado que "el interés superior del niño es un concepto dinámico", cuyo objeto es "garantizar el disfrute pleno y efectivo de todos los derechos reconocidos por la Convención y el desarrollo holístico del niño", a fin de tutelar su "integridad física, psicológica, moral y espiritual" y de "promover su dignidad humana". Además el mismo Comité ha advertido que "el interés superior del niño es un concepto triple", y que en consecuencia se le debe considerar comprensivo de tres dimensiones, a saber: i) un "derecho subjetivo", ii) un "principio jurídico interpretativo fundamental", y iii) una "norma de procedimiento" (cfr. Observación General n ${ }^{\circ}$. I4 [2013] sobre el derecho del niño a que su interés superior sea una consideración primordial [art. 3.I], párrs. 4-7 y II).

El referido instrumento internacional dispuso en su artículo 8.2 que los "pueblos indígenas 
Es precisamente este proceso de "internacionalización” del derecho, que impone el análisis de los textos legales -e incluso, a veces, de los constitucionales-desde la óptica de los derechos humanos, la principal innovación introducida por el "nuevo constitucionalismo" en el ámbito del derecho de familia respecto de la "primera oleada" del reformismo constitucional latinoamericano ${ }^{5}$. Las consecuencias más evidentes e importantes de esta nueva perspectiva, que pone el acento en la dignidad, autonomía, igualdad y no discriminación de las personas, están representadas por el paso $57:$ i) de un modelo de familia "totalizante" ${ }^{8}$ (de tipo patriarcal), basado en la autoridad paterno-marital y donde se privilegiaba

deberán tener el derecho de conservar sus costumbres e instituciones propias, siempre que éstas no sean imcompatibles con los derechos fundamentales definidos por el sistema jurídico nacional ni con los derechos humanos internacionalmente reconocidos". Este mandato, que ya estaba contenido en algunas Constituciones latinoamericanas anteriores al referido Convenio (cfr., p. ej., CPan/ı 972, art. 90; CNic/r 986, art. 5[3]; CBra/ı988, art. 23r), fue ampliamente acogido luego por muchas de ellas (cfr., p. ej., CMéx/1917-1992, art. 2; CPar/1992, art. 63; CGua/I 993, art. 66; CArg/I 853-I 994, art. 75.I 7; CVen/ı999, art. I I 9; CEcu/2008, art. 57.I, 9 y го; CBol/2009, art. 30.II.2 y 5) y extendido también, por algunas de las más recientes, a los grupos de orígen africano (cfr., p. ej., CEcu/2008, art. 58; CBol/2009, art. 32 ).

56 Emblemática al respecto resulta, p. ej., la sentencia 0058 del Tribunal Constitucional boliviano, del 25/06/2003, por la cual se declaró inconstitucional el artículo 99[2] del Código de la familia de 1972 que otorgaba solamente a uno de los cónyuges (marido) la posibilidad "particular" de obtener la restricción para que el otro cónyuge (esposa) se abstenga de ejercer profesiones u oficios por razones de moralidad o de perjuicio a la comunidad familiar, por considerarlo violatorio de los principios de igualdad y no discriminación reconocidos (en general, a todos las personas, sin distinción entre hombres y mujeres y, en especial, a los cónyuges, sin diferenciar entre esposos y esposas) por los artículos 6 y r 94 .I de la entonces CBol/r r995, y por la Convención Americana sobre Derechos Humanos y el Pacto Internacional sobre Derechos Civiles y Políticos (cfr. texto integral de la sentencia en <gestor.pradpi.org/download.php?id_doc=2462> [consultado el 24/07/201 5]). En sentido similar se expresó la Corte Constitucional colombiana -entre otras- en la sentencia C-507 del 25/05/2004 por la que se declaró inexequible el artículo I40.2 del CcCol/1859-I 887, según el cual el matrimonio era nulo cuando se había contraído entre un "varón menor de catorce años" y una "mujer de doce", por considerar que el mismo "afecta en alto grado (I) el derecho al desarrollo libre armónico e integral de las menores y el pleno ejercicio de sus derechos, (2) el derecho a que el Estado adopte las medidas de protección adecuadas y necesarias para garantizar tales derechos, y (3) el derecho a la igualdad de protección de los niños y las niñas", tal como reconocen los artículos 5, I3, 43 y 44 de la CCol/r 99 I, la "Convención sobre la eliminación de todas las formas de discriminación contra la mujer" y la Convención sobre los Derechos del Niño (cfr. texto integral en $<$ http://www. corteconstitucional.gov.co/relatoria/2004/C-507-04.htm> [consultado el 24/07/2015]).

57 Cfr., entre otros, Miguel Ángel Ciuro Caldani, "Filosofía del Derecho de Familia”, en Investigación y Docencia, vol. 34, Rosario (Argentina), 200 I, pp. I 5 ss.; ID., "Aportes de la Filosofía del Dereho al Derecho de Familia", en Investigación y Docencia, vol. 48, Rosario (Argentina), 20I4, pp. I3 ss.; Marco Navarro, ob. cit., pp. 9 ss., y Nuria González Martín, "Modelos familiares ante el nuevo orden jurídico: una aproximación casuística”, en Miguel Carbonell, José Carbonell y Nuria González Martín (coords.), Las familias en el siglo XXI: una mirada desde el derecho, México, D.F., 2012 , p. 57.

$5^{8}$ Esta terminología es empleada por Flavia Marco Navarro, Legislación comparada en materia de familias. Los casos de cinco países de América Latina, Cepal - Serie Políticas Sociales, n. ${ }^{\circ}$ I 49, Santiago de Chile, 2009, p. 8. 
el interés general de la institución familiar (identificado generalmente con el del jefe de familia), a otro más "democrático", fundado en la solidaridad y que tiene en cuenta también los intereses particulares de sus miembros ${ }^{59}$ (principalmente de aquellos más débiles, como son la mujer y los niños) ${ }^{60}$; y ii) de "la familia" a "las familias", es decir, de un modelo "único" de familia (el "tradicional", heterosexual y fundado principalmente en el matrimonio) a una "pluralidad" de modelos o de comportamientos familiares ${ }^{6 \mathrm{I}}$ (el de la familia basada en una unión convivencial, la constituida por personas del mismo género, la monoparental, la esamblada, la ampliada, la indígena, etc. $\left.{ }^{62}\right)^{63}$.

59 Tal dicotomía ha permitido distinguir entre los "derechos (sociales) de la familia" (cfr. supra nota $3^{8}$ ) y los "derechos familiares de la persona" (sobre lo cual remitimos, entre otros, a Manuel Chávez Asencio, La familia en el derecho: Derecho de Familia y relaciones jurídicas familiares, México, D.F., I984, pp. 38 I ss.; ID., "Alternativas constitucionales para la familia del siglo xxı", Revista Mexicana de la Procuración de fusticia, vol. I, México, D.F., I997, pp. I I 3 ss., y Érén Chávez Hernández, "La protección constitucional de la familia. Una aproximación a las Constituciones latinoamericanas", en Rosa María Álvarez de Lara [coord.], Panorama internacional de Derecho de Familia. Culturas y sistemas jurídicos comparados, t. I, México, D.F., 2006, pp. I 28 ss.).

60 Cfr., entre otros, Marco Navarro, ob. cit., pp. i6 ss., y Nora Lloveras y Marcelo Salomón, El derecho de familia desde la Constitución Nacional, Buenos Aires, 2009, p. 4I, quienes destacan que "El impacto de los DDHH en las relaciones familiares se observa a partir de la visión de la persona como eje de protección y no de la institución de la familia en sî". También parecerían responder a esta idea las disposiciones de algunas Constituciones latinoamericanas que, no obstante calificar a la familia como "asociación natural", "base" o "núcleo fundamental", o "fundamento" de la sociedad (CSal/r983, art. 32; CCol/r991, art. 42[r]; CVen/r999, art. 75 [r]; CEcu/2008, art. 67; CBol/2009, art. 62; $\mathrm{CRD} / 2010$, art. 55), terminan considerándola también como el "espacio básico" o "fundamental" para el "desarrollo integral de las personas" (CVen/I999, art. 75[I]; CRD/20IO, art. 55) y/o disponen que la ley regulará las relaciones de los cónyugues entre sí y de ellos y sus hijos, "estableciendo los derechos y deberes recíprocos sobre bases equitativas" (cfr. la CSal/r 1983 , art. 33), o que las relaciones familiares "se basan en el respeto recíproco de todos sus integrantes" (CCol/r99i, art. 42 [3]), o en la "igualdad de derechos, deberes y oportunidades" de los mismos (CEcu/2008, art. 67; CBol/2009, art. 62) o, más detalladamente, en "la solidaridad, el esfuerzo común, la comprensión mutua y el respeto recíproco" de los miembros del grupo familiar (CVen/r999, art. 75[I]). Esta concepción parecería ser recogida también por el artículo 3 de la Ley venezolana 38.773 de 2007 que define la familia como "la asociación natural de la sociedad y espacio fundamental para el desarrollo de sus integrantes" (cfr. supra nota 3).

6I En el derecho constitucional latinoamericano se han hecho eco de esta nueva orientación -al menos nominalmente- la CVen/r 1999, que intitula su Capítulo v "Derechos Sociales y de "las Familias" (así como también la Ley 38.773 de 2007 para la "Protección de 'las familias', la maternidad y la paternidad"); la CEcu/2008, cuyo artículo 67 dispone que "Se reconoce la familia en sus diversos tipos"; y la CBol/2009, que dedica su Sección vi a los "Derechos de las familias" (lo que también se vio reflejado en el título y contenido del Anteproyecto de "Código de 'las familias' y del Proceso familiar" del Estado Plurinacional de Bolivia de 2013).

62 Algunas Constituciones refieren también a otros tipos de familia, como la "numerosa" (cfr., p. ej., CUru/1967, art. 4I; CPar/1992, art. 53[3]) y la "disgregada" (cfr., p. ej., CEcu/2008, art. 69.4), a las que se las considera sujetas a una protección especial por parte del Estado.

63 Es que, como bien ha expresado el Tribunal Constitucional peruano, en sus sentencias del 30/06/2007 (Exp. 09332-2006-PA/TC) y del 30/o6/2010 (Exp. 04493-2008-PA/TC), "los cam- 
Es por ello que con razón se ha afirmado que, siendo la familia una noción más sociológica que jurídica, el Estado tendría que renunciar a imponer un modelo único de comportamiento familiar, y debería en cambio preocuparse por dar cobertura a las diferentes opciones que puede tomar toda persona en uso de su autonomía y/o de acuerdo a su propia cultura y convicciones, con el único límite impuesto por el respeto de los derechos humanos, abriendo el ordenamiento jurídico para hacerlo capaz de tutelar a todas las formas de familia sin discriminaciones de ningún tipo, favoreciendo con ello la instauración de un modelo pluralista en el cual -como ya hemos expresado- los criterios mayoritarios no sean impuestos coactivamente a las minorías ${ }^{64}$.

Por último, cabe señalar que los organismos internacionales encargados de monitorear y/o aplicar los tratados sobre derechos humanos han reconocido también -directa o indirectamente y en forma más o menos amplia- que la tutela de la familia prevista en ellos debe ser extendida a la pluralidad de formas en las que la misma puede presentarse en el ámbito de la realidad social. Así, el Comité de Derechos Humanos de Naciones Unidas, al interpretar el mandato de protección previsto por el artículo 23 del Pacto de Derechos Civiles y Políticos de i966, exige que se incluya dentro del concepto de familia no solo a aquella organizada con base en el matrimonio, sino también a las conformadas por una pareja no casada e incluso a las familias monoparentales ${ }^{65}$. Por su parte, la sentencia de la Corte Interamericana de Derechos Humanos del 24/02/201 2, en

bios sociales y jurídicos tales como la inclusión social y laboral de la mujer, la regulación del divorcio y su alto grado de incidencia, las grandes migraciones hacia las ciudades, entre otros aspectos, han significado un cambio en la estructura de la familia tradicional nuclear, conformada alrededor de la figura del pater familias. Consecuencia de ello es que se hayan generado familias con estructuras distintas a la tradicional, como son las surgidas de las uniones de hecho, las monoparentales o las que en doctrina se han denominado familias reconstituidas"; pero concluyendo la última de las decisiones citadas que "de lo expuesto no debe deducirse que la familia se encuentra en una etapa de descomposición, sino de crisis, de transformación; se trata por el contrario de la normal adaptación de esta institución a los rápidos cambios sociales, políticos, históricos y morales de la mayoría de la población" (cfr., respectivamente, <http:// www.tc.gob.pe/jurisprudencia/2008/09332-2006-AA.html> [consultado el 24/07/201 5], fudamento $7 \mathrm{y}<$ http://www.tc.gob.pe/jurisprudencia/2010/04493-2008-AA.html>, fundamento 8 [consultado el 24/07/2015]).

64 Cfr., en este sentido, Miguel Carbonell, "Familia, Constitución y derechos fundamentales", en Álvarez De Lara (coord.), Panorama internacional de Derecho de Familia. Culturas y sistemas jurídicos comparados cit., pp. 82, 86 y 89, y Guillermina Zavala, "Exigencias de una Derecho de Familia que brinde nuevas respuestas jurídicas", en Trabajos del Centro, Centro de Investigaciones de Derecho Civil - unr, Segunda Serie, $n^{\circ} .9 /$ ro, Rosario (Argentina), 20 I I, p. 3 I.

$65 \mathrm{Al}$ recomendar que, "En vista de los diversos tipos de familia, como las parejas que no han contraído matrimonio y sus hijos y las familias monoparentales, los Estados partes deberían indicar [en los informes que los mismos rindan ante el Comité] en qué medida la legislación y las prácticas nacionales reconocen y protegen a esos tipos de familia y a sus miembros" (cfr. Observación General n. ${ }^{\circ}$ I9 [1990] sobre la familia [art. 23], párr. 2, en Miguel Carbonell, SANdra Moguel y Karla Pérez Portillo [comps.], Derecho Internacional de los Derechos Humanos. Textos básicos, t. I, México, D.F., 2003, pp. 426 ss.). 
el caso "Atala Riffo y niñas vs. Chile”, parece abrir la puerta al reconocimiento como familia de las uniones entre personas del mismo género ${ }^{66}$, al considerar que toda discriminación por razón de orientación sexual -en el contexto familiar- es contraria a la Convención Americana sobre Derechos Humanos de ig69 (art. I.I), en atención a que en ella no existe un modelo estereotipado o específico de familia (como podría ser la denominada "familia tradicional") ${ }^{67}$ sino que, de acuerdo con la constatación de la misma Corte,

... en el marco de las sociedades contemporáneas se dan cambios sociales, culturales e institucionales encaminados a desarrollos más incluyentes de todas las opciones de vida de sus ciudadanos, lo cual se evidencia en la aceptación social de parejas interraciales, las madres o padres solteros o las parejas divorciadas, las cuales en otros momentos no habían sido aceptadas por la sociedad. En este sentido, el Derecho y los Estados deben ayudar al avance social, de lo contrario se corre el grave riesgo de legitimar y consolidar distintas formas de discriminación violatorias de los Derechos Humanos ${ }^{68}$.

\section{Los diversos modelos familiares resultantes del derecho constitucional latinoamericano vigente}

\section{A. La familia matrimonial}

La familia constituida sobre la base del matrimonio es, en principio, la que menos problemas presenta, pues al responder al denominado modelo familiar "tradicional" (identificado además con la heterosexualidad de los cónyuges) se encuentra reconocida expresa o implícitamente por todos los textos constitucionales latinoamericanos vigentes, e incluso en muchos de ellos todavía se la sigue privilegiando; esto al afirmarse que el matrimonio es la "base esencial",

66 Cfr. Corte IDH, caso "Atala Riffo y niñas vs. Chile”, Fondo, reparaciones y costas, Sentencia del 24 de febrero de 2012 , Serie C, n. ${ }^{\circ} 239$, párrs. I 74-I 77, pp. 56 s. Sobre esta sentencia (cuyo texto integral puede consultarse en <http://www.corteidh.or.cr/docs/casos/articulos/ seriec_239_esp.pdf> [consultado el 24/O7/2015]) remitimos, entre otros, a JeAnnetTe LlaJA Villena y Beatriz Ramírez Huaroto, "Profundizando la igualdad desde la orientación sexual. A propósito de la sentencia de la Corte Interamericana de Derechos Humanos del caso Karen Atala e hijas contra Chile”, en Gaceta Constitucional, n. ${ }^{\circ}$ 54, Lima, 20 I 2, pp. 32 I ss.

67 Ibíd., párr. I45, p. 5 ०.

68 Ibíd., párr. I 20, p. 42. En el mismo sentido la Corte observa también que, "si bien es cierto que ciertas sociedades pueden ser intolerantes a condiciones como la raza, el sexo, la nacionalidad o la orientación sexual de una persona, los Estados no pueden utilizar esto como justificación para perpetuar tratos discriminatorios", sino que "están internacionalmente obligados a adoptar las medidas que fueren necesarias 'para hacer efectivos' los derechos establecidos en la Convención” (párr. I I9, p. 42). 
el "fundamento" o "uno de los componentes fundamentales" de la familia ${ }^{69} \mathrm{o}$, directamente, que el Estado lo "protege" 70 y/o que la Comunidad y el Estado lo "promueven"71.

Asimismo cabe señalar que casi la totalidad de las Constituciones de la Región que regulan este modelo de familia otorgan efectos jurídicos solo al denominado "matrimonio civil" -no obstante reconocer todas ellas la libertad de culto o creencias, y muchas de las mismas las prácticas, costumbres y tradiciones de los pueblos indígenas (cfr. infra II.G)-, con las únicas excepciones de la CBra/ı 988 (art. 226.2), la CCol/I99I (art. 42 [8y ro]), la CGua/I 993 (art. 49) y la CRD/20Io (art. 55.4), que admiten también expresamente el matrimonio religioso y al cual le reconocen efectos civiles en los términos que establezca la ley. Este proceso de laicización del matrimonio ha conducido además al reconocimiento de la disolubilidad del mismo, lo que incluso está previsto explícitamente por algunas Cartas constitucionales latinoamericanas, la mayoría de las cuales admite el divorcio no solo como sanción sino también como remedio ${ }^{72}$.

La familia así constituida podría estar integrada además por los hijos de la pareja, sean ellos procreados naturalmente o adoptados ${ }^{73}$. En cambio, la filiación natural asistida (es decir, la que reconoce su fuente en el empleo de las técnicas de reproducción humana asistida en sus múltiples aplicaciones) solo está referida expresamente por la CCol/I99I (art. 42[5]), lo que pone de manifiesto la perplejidad de los ordenamientos latinoamericanos en esta materia 74.

69 Cfr., p. ej., la cCR/1949, art. 52; la CSal/1983, art. 32; la CPar/1992, art. 52 .

70 Cfr., p. ej., la CPan/ı972, art. 56[r]; la CCub/ı 976, art. 35; la Ven/ı999, art. 77; la CRD/20 Io, art. $55 \cdot 3$.

7I Cfr., p. ej., la CPer/r993, art. 4[I]; la CRD/20Io, art. 55.3.

72 Cfr., p. ej., la CCub/1976, art. 36 [2]; la CHon/ı982, art. I I 3; la CNic/ı 986, art. 72; la CBra/ı 988 , art. 226.6; la CCol/I99I, art. 42 [7y9]; la CPar/I992, art. 5 I; la CPer/I993, art. 4[2]; la CRD/20IO, art. 55.10.

73 Tal como admiten expresamente, p. ej., la CHon/ı 982 , art. i r6; la CSal/1983, art. 36[r]; la CNic/ı 986, art. 79; la CBra/I988, art. 22 7.6; la CCol/r 991, art. 42 [5]; la CGua/ı 993, art. 54; la CVen/r 999, art. 75[2]; la CEcu/2008, arts. 68 y 69.6; la CBol/2009, art. 59; la CRD/2010, art. 55.I2.

74 De especial interés sobre este particular resulta la sentencia (Serie C, $\mathrm{n}^{\circ} .257$ ) de la Corte Interamericana de Derechos Humanos del 28/I i/20I 2 en el caso "Artavia Murillo y otros ('Fecundación in vitro') vs. Costa Rica", en la que se condenó al país demandado por la sentencia dictada el I 5/03/2000 por la Sala Constitucional de su Suprema Corte de Justicia (que reconociéndole personalidad jurídica al embrión había declarado la inconstitucionalidad del Decreto presidencial n. ${ }^{\circ} 24029-\mathrm{S}$ de 1995 que regulaba la fecundación in vitro) por vulnerar la misma los artículos I.I (derecho de no discriminación), 5.I (derecho a la integridad física y psicológica), 7 (derecho a la libertad personal), i (derecho a la vida privada y familiar) y I 7.2 (derecho a fundar una familia) de la Convensión Interamericana de los Derechos Humanos de I969. Asimismo esta sentencia interpreta, por primera vez y sin aplicar la doctrina del margen de apreciación a la decisión del caso concreto, el artículo 4.I de la Convención (que protege el derecho a la vida "en general, a partir del momento de la concepción") en el sentido de que cuando se emplean técnicas de reproducción humana asistida debe entenderse 
Empero la cuestión más discutida de este modelo familiar está representada por la posibilidad de la admisión del matrimonio entre personas del mismo género (cfr. infra II.C), expresamente prohibido por la CHon/1982-2004 (art. i I 2) y excluido también por la CCub/1976 (art. 36), la CNic/ı986 (art. 72), la CCol/rg9i (art. 42[r]), la CPar/r992 (art. 51[r]), la CVen/r999 (art. 77), la CEcu/2008 (art. 67), la CBol/2009 (art. 63.I) y la CRD/2010 (art. 55.pr), las cuales, al mantenerse apegadas a la tradición "romano-canónica", circunscriben los alcances de la institución matrimonial a la unión entre un hombre y una mujer (D. 23,2,I [Modestino]; D. I, I,3 [Ulpiano]; J. I, I,9; Siete Partidas 4,2,I).

\section{B. La familia convivencial}

Siguiendo la tradición inaugurada por el constitucionalismo social latinoamericano (cfr. supra I.A), muchos textos constitucionales de la Región reconocen expresamente la familia constituida mediante una unión convivencial75, "libre" o "de hecho" (siempre que la misma reúna ciertas condiciones, como la ausencia de impedimentos matrimoniales, la durabilidad, la singularidad y la estabilidad), a la que también algunas de ellas equiparan directamente al matrimonio civil ${ }^{76}$.

que la "concepción" tiene lugar cuando el embrión se implanta en el útero (interpretación esta que -según el criterio de la Corte- permitiría alcanzar "un adecuado balance entre [los] derechos e intereses en conflicto"). Sobre los alcances de esta sentencia (cuyo texto integral se encuentra disponible en <http://www.corteidh.or.cr/docs/casos/articulos/seriec_257_esp. pdf> [consultado el 24/o7/20 I 5]) cfr., entre otros, Beatriz Ramírez Huaroto, "Los derechos reproductivos en la jurisprudencia de la Corte Interamericana de Derechos Humanos. Apuntes sobre la sentencia en el caso Artavia Murillo y otros contra Costa Rica”, Gaceta Constitucional, n. ${ }^{\circ}$ 6r, Lima, 20 I 3, pp. 366 ss., y Eduardo Chía y Pablo Contreras, "Análisis de la sentencia "Artavia Murillo y otros ('Fecundación in vitro') vs. Costa Rica" de la Corte Interamericana de Derechos Humanos", Estudios Constitucionales, año I 2, n. ${ }^{\circ}$, Santiago de Chile, 20 I 4 pp. 567 ss.

75 De las diversas expresiones empleadas para designar a esta tipología familiar preferimos usar aquí la del nuevo Código civil y comercial de Argentina de 2014 (arts. 509-528); sobre la cual remitimos a Kemelmajer de Carlucci, Las nuevas realidades familiares en el Proyecto de Código civil y comercial argentino, cit., pp. I Io ss.

76 Cfr., p. ej., CPan/ı972, art. 58; CBra/ı 988, art. 226.3; CPar/ı992, art. 5 I [2]; CVen/ı 999, art. 77. Sin embargo, cabe señalar que una sentencia de la Sala Constitucional del Tribunal Supremo de Justicia de Venezuela del I 5/07/2005 ha limitado los alcances de la equiparación prevista por el artículo 77 de la CVen/I 999 al exigir que "para reclamar los posibles efectos civiles del matrimonio, es necesario que la 'unión estable' haya sido declarada conforme a la ley, por lo que se requiere una sentencia definitiva firme que la reconozca [...] dictada en un proceso con ese fin" (cfr. <http://www.tsj.gov.ve/decisiones/scon/julio/I682-I 50705-04-330 I.HTM>, p. 8 [consultado el 24/O7/20 I 5]). En sentido contrario a su par venezolano se ha expresado en esta misma materia el Pleno del Tribunal Constitucional del Perú, en las sentencias del I 4/04/2000 (Exp. 0498-1999-AA/TC) y del 30/06/2010 (Exp. 04493-2008-PA/TC), en las cuales se estableció que la convivencia podía acreditarse por cualquier medio de prueba (p. ej., testimonio de vecinos, partida de matrimonio religioso), no obstante que diversas sentencias del Poder Judicial peruano hayan requerido para la prueba de ese estado una sentencia judicial (cfr., respectivamente, <http://www.tc.gob.pe/jurisprudencia/2000/00498-I999-AA.html>, fundamento 5 [consultado 
El reconocimiento de efectos jurídicos a la unión convivencial comprende no solo lo que respecta a las relaciones personales y patrimoniales de la pareja, abarcando también todo lo concerniente a sus hijos naturales y/o adoptados77, a quienes se reconocen -sin ningún tipo de discriminación- los mismos derechos que a los hijos concebidos dentro del matrimonio ${ }^{78}$; garantizándoseles, además, que no se dejará constancia alguna de la naturaleza de la filiación en ningún documento oficial, así como tampoco del estado civil de los progenitores ${ }^{79}$.

Sin embargo, también con relación a este modelo familiar el punto más debatido es el que se relaciona con el reconocimiento de las uniones convivenciales entre personas del mismo género. Sin perjuicio de lo que diremos al ocuparnos en particular de la familia homoparental (cfr. infra II.c), cabe señalar aquí que de los textos constitucionales latinoamericanos que se refieren de manera expresa a la unión convivencial se deduciría que: i) uno de ellos la prohíbe directamen$t^{8 \circ}$; ii) otros también lo harían, pero indirectamente, al exigir que la pareja de convivientes esté formada por un hombre y una mujer ${ }^{8}$; iii) uno, en cambio, la admitiría, pero a contrario sensu ${ }^{82}$; y iv) los restantes harían lo mismo que este último, pero de manera implícita, al no exigir expresamente que los integrantes de la pareja de convivientes sean de diferente género ${ }^{83}$.

\section{La familia homoparental}

Como acabamos de ver al tratar las dos tipologías familiares precedentes, la familia homoparental -es decir aquella constituida por una pareja formada por

el 24/O7/20I 5], y <http://www.tc.gob.pe/jurisprudencia/2010/04493-2008-AA.html>, fundamento I I [consultado el 24/o7/2015]), en atención a que -como el mismo Tribunal indicó en otra oportunidad-, "pese a la promoción del instituto del matrimonio [cfr. art. 4 CPer/I 993], se ha llegado a constitucionalizar una situación fáctica muy concurrente en el país pues existen familias que están organizadas de hecho, sin haberse casado civilmente" (cfr. sentencia del

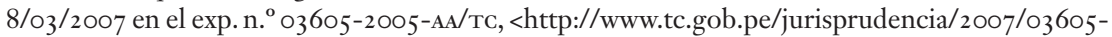
2005-AA.html>, fundamento 3 [consultado el 24/07/20 I 5]).

77 Cfr., p. ej., la CHon/ı 982, art. i i6; la CNic/ı 986, art. 79; la CBra/ı988, art. 227.6; la CCol/ı 99 I, art. 42 [ry5]; la CGua/ı 993, art. 54; la CEcu/2008, art. 68i.f.; la CBol/2009, art. 63.II; la CRD/20IO, art. 55.I2

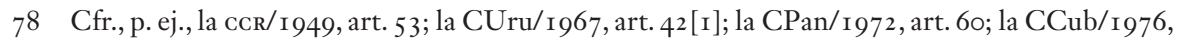

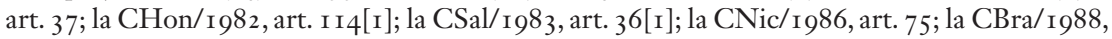
art. 227.6; la CCol/I99I, art. I3[I] y 42 [6]; la CPar/I992, art. 53; la CGua/I993, art. 50; la CPer/I 993, art. 6[3]; la CEcu/2008, art. 69.6; la CBol/2009, art. 59.III; la CRD/20IO, art. 55.9[r].

Cfr., p. ej., la CPan/1972, art. 6r; la CCub/1976, art. 37; la CHon/1982, art. I I4[2]; la CSal/1983, art. 36 [2]; la CNic/ı 986, art. 75 ; la CBra/ı 988, art. 227.6 ; la CPar/I992, art. 53; la CPer/ı 993 , art. 6[3]; la CEcu/2008, art. 69.7; la CRD/2010, art. 55.9[2].

80 Cfr. CHon/I982-2004, art. I I 2.

8I Cfr. CSal/1983, art. 33i.f.; CNic/I986, art. 72; CBra/ı988, art. 226.3; CPar/I992, art. 5 I [2]; CPer/1993, art. 5; CVen/1999, art. 77; CRD/2010, art. 55[pr.y5].

$82 \mathrm{Cfr} . \mathrm{CEcu} / 2008$, art. 68i.f.

83 Cfr. CPan/ı 972 , art. 58, CCol/ı99ı, art. 42[ri.f.]; CGua/ı 993, art. 48. 
personas del mismo género y vinculadas entre sí mediante el matrimonio o una unión convivencial- solo está prevista expresamente por dos textos constitucionales latinoamericanos: i) uno, el art. i i 2 de la CHon/I 982 (reformado por el Decreto I 76/2004 y ratificado por el Decreto 36/2005), que refiere a ella directamente al disponer: "Se prohibe el matrimonio y la unión de hecho entre personas del mismo sexo ${ }^{84}$. Los matrimonios o uniones de hecho del mismo sexo celebrados bajo las leyes de otros países no tendrán validez en Honduras"85; ii) otro, en cambio, esto es, el art. 68 de la CEcu/2008, lo hace indirectamente, ya que luego de disponer que "La unión estable y monogámica entre dos personas libres de vínculo matrimonial que formen un hogar de hecho, por el lapso y bajo las condiciones y circunstancias que señale la ley, generará los mismos derechos y obligaciones que tienen las familias constituidas mediante matrimonio", aclara que "La adopción corresponderá sólo a parejas de distinto sexo", de lo que se deduciría -en sentido contrario- que las uniones convivenciales entre personas del mismo género también estarían reconocidas constitucionalmente pero con el único límite del derecho de adopción (el que corresponde solo a las parejas de diferente sexo, sea que estas constituyan una familia matrimonial o una convivencial) $)^{86}$.

84 En el ámbito del derecho secundario, sigue también una orientación similar el reciente Código de Derecho Internacional Privado de Panamá de 2014, cuyo artículo 40 dispone que "Se prohibe el matrimonio entre individuos del mismo sexo".

85 Lo mismo podría deducirse, indirectamente, de aquellas Constituciones latinoamericanas que caracterizan el matrimonio como la unión entre un hombre y una mujer (cfr. CPar/1972, arts. 49, 5 I y 52; CNic/I986, art. 72; CCol/r99I, art. 42 [I]; CVen/1999, art. 77; CBol/2009, art. 63; CRD/20IO, art. 55.pr. y 5). Sin embargo, diversa fue la solución a la que arribó la Corte Constitucional colombiana interpretando el artículo 42[I] de la CCol/I99I (cfr. infra nota IOO).

$86 \mathrm{Al}$ respecto cabe recordar, sin embargo, que la Corte Interamericana de Derechos Humanos, en la causa "Atala Riffo y niñas vs. Chile" (24/O2/20 2 2), ha precisado que la orientación sexual "no tiene relevancia para analizar aspectos relacionados con la buena o mala paternidad", y que "no son admisibles las consideraciones basadas en estereotipos por la orientación sexual, es decir, pre-conceptos de los atributos, conductas o características poseídas por las personas homosexuales o el impacto que estos presuntamente puedan tener en las niñas y los niños" (cfr. <http://www.corteidh.or.cr/docs/casos/articulos/seriec_239_esp.pdf>, párrs. I09, i I I y i67, y pp. 39 s. y 54 [consultado el 24/o7/2015], y Llaja Villena y Ramírez Huaroto, ob. cit., pp. 326 s). La Corte cita en apoyo de su decisión en esta materia (párr. I 26) una sentencia de la Suprema Corte de Justicia de México del i6/08/2010 (cfr. infra nota 82) en la que se rechazó un pedido de inconstitucionalidad de la reforma introducida en 2009 al artículo 39I del CcMéxDF/I 928 , por la que se reconociera el derecho a adoptar a las parejas del mismo sexo (cfr. scjN, Acción de inconstitucionalidad A.I. 2/20 Io, en <www2.scjn.gob.mx/juridica/engroses/ cerrados/207/10000020.019.doc>, párrs. 336 y 338, pp. I 40 s. [consultado el 24/07/2015], y Alejandro Rosas Martínez, "Algunas implicaciones jurídicas del matrimonio entre personas del mismo sexo en la Ciudad de México", Revista Derecho del Estado, n. ${ }^{\circ}$ 26, Bogotá, 20 I I, pp. I 99 ss.). En el mismo sentido se ha pronunciado recientemente la Corte Constitucional de Colombia en la sentencia SU-6I 7 del 28/08/20I4 en la que se concluyó que la exclusión de "la posibilidad de la adopción por consentimiento con fundamento en el carácter homosexual de la pareja requirente vulnera los derechos a la autonomía familiar y a tener una familia, por 
Ahora bien, aun cuando no refieran expresamente a este modelo de familia, consideramos que la misma estaría admitida también por las Cartas constitucionales que no exigen la diferencia de sexo de los contrayentes como requisito para contraer matrimonio ${ }^{87}$; así como también por aquellas que han optado por una regulación más minimalista de las relaciones familiares ${ }^{88}$, en cuyos ordenamientos jurídicos los poderes públicos estarían facultados para admitir la familia homoparental convivencial o-incluso- la matrimonial ${ }^{89}$.

Sin embargo, como ya hemos adelantado, el reconocimiento de la familia homoparental (en cualquiera de sus modalidades) constituye en la práctica una cuestión de política del derecho, que no depende solo de la interpretación y aplicación de las disposiciones constitucionales sobre la familia, sino también de las que garantizan el libre desarrollo de la personalidad ${ }^{\circ}$, la igualdad y la no discriminación ${ }^{91}$ (sobre todo aquella motivada en la "orientación" o "preferencia" sexual de la persona ${ }^{92}$ ), al igual que de la aplicación del principio de reserva

cuanto se desconoce, sin razón que lo justifique, la existencia de un arreglo familiar en el que el menor, por voluntad de su padre o madre biológicos, comparte la vida con el compañero o compañera del mismo sexo de aquél y en el que se conforma un vínculo sólido y estable entre ellos, a partir del cual el adulto asume las obligaciones y deberes asociados al vínculo filial" (cfr. Comunicado n. ${ }^{\circ}$ 35, en <http://www.corteconstitucional.gov.co/comunicados/No.\% 20 $35 \% 20$ comunicado $\% 2028 \% 2$ ode $\%$ 2oagosto $\% 2$ ode \% 202014 .pdf>, párr. 3, p. 2 [consultado el 24/O7/20I5]). Es de destacar que esta misma Corte, en la sentencia T-276 de 20r 2, ya había amparado los derechos de un padre adoptante homosexual (cfr. texto integral en <http:// www.corteconstitucional.gov.co/relatoria/2OI2/t-2 76-I2.htm> [consultado el 24/O7/20I5], y las consideraciones sobre la misma en Manuel Fernando Quinche Ramírez y Angélica Armenta Ariza, "Igualdad, razonabilidad y género en los procesos de constitucionalización e internacionalización del derecho", Estudios Socio-furídicos, n. ${ }^{\circ}$ I4, Bogotá, 20 I 2, p. 59).

87 Cfr. ccr/ı940, art. 5 I; CPan/ı972, art. 57; CSal/ı983, art. 32; CBra/ı 988, art. 226. I; CGua/ı993, arts. 47 y 49). Hay Constituciones donde tampoco se exige la diferencia de sexo para constituir una unión convivencial (cfr. CPan/ı 972, art. 58; CCol/ı 99 I, art. 42 [ı i.f]; CGua/ı 993, art. 48. También integraría esta última categoría la CCub/ı976 (art. 36), la que solo se limita a definir el matrimonio (como "la unión voluntariamente concertada de un hombre y de mujer"), guardando silencio - en cambio- sobre la unión convivencial, la que por lo tanto podría estar integrada en cambio por personas del mismo género.

88 Cfr. CArg/ı 853-I957, art. I4bis; CUru/ı967, art. 40; CMéx/ı9ı7-I974, art. 4; CCh/ı98ı, art. I.

89 Como efectivamente ya ha sucedido en algunos ordenamientos latinoamericanos, tales como los de Argentina, Brasil, Colombia, Uruguay, Chile, del Distrito Federal de México y de las entidades federativas mexicanas de Coahuila y Quintana Roo.

90 Cfr., p. ej., la CCol/ı99 I, art. I6; la CVen/ı999, art. 20; la CEcu/2008, art. 66.5; la CRD/2010, art. 43 .

9I Cfr., p. ej., la CUru/ı967, art. 8; la cCR/ı 949-ı968, art. 33; la CPan/ı972, art. i 9; la CCub/ı976, art. 42; la CCh/ı 98 I, arts. I 9.2 y 3 ; la CHon/ı 982 , art. 6o; la CSal/ı 983 , art. 3 ; la CNic/ı 986, art. 2 7; la CBra/ı 988, arts. 3.IV y 5; la CCol/ı 99 I, arts. 5 y I 3; la CGua/ı 993, art. 4; la CPer/ı 993 , art. 2.2; la CArg/I 853-I 994, arts. I6 y 75.23[I]; la CVen/I 999, art. 2 I. I y 2; la CEcu/2008, art. 66.4 ; la $\mathrm{CRD} / 2010$, art. 39 .

92 Cfr., p. ej., la CEcu/2008, art. i i.2; la CBol/2009, art. I4.II; la CMéx/I 9 I 7-20 i I, art. I[3]. 
(según el cual todo lo que no está prohibido está permitido)93 y de los criterios hermenéuticos pro bomine y de progresividad (cfr. supra I.A).

Así, la Sala Constitucional del Tribunal Supremo de Justicia de Venezuela, en la sentencia $n .^{\circ}$ I 90 del 28/02/2008 ${ }^{[94]}$, rechazó la aplicación extensiva de los efectos patrimoniales atribuidos a las uniones convivenciales heterosexuales a las uniones constituidas entre personas del mismo género, afirmando que la no aplicación a las segundas del régimen de protección reforzado establecido a favor de las primeras en el artículo 77 de la CVen/ı999 no vulnera el principio de igualdad previsto en el artículo 2 I. I ibíd., por no implicar esa diferenciación un trato discriminatorio (en razón de la orientación sexual de las personas). Lo anterior en atención a que, según una reiterada jurisprudencia de esta misma Sala, lo constitucionalmente prohibido es el trato desigual frente a situaciones idénticas, no el desigual frente a situaciones desiguales; en efecto, si bien existe igualdad sustancial (aunque no formal) entre matrimonio y concubinato (de ahí la equiparación que de ambas instituciones hace el texto constitucional venezolano), no sucedería lo mismo entre ellas y las uniones entre personas de igual género ${ }^{95}$. De manera similar se expresó el Tribunal Constitucional de Chile que, en la sentencia rol n. ${ }^{\circ}$ I 88 I-Io, dictada el 3/I I/20 I I ${ }^{[96]}$, rechazó declarar

93 Cfr., p. ej., la CArg/ı 853, art. 19; la CUru/ 1967, art. ıо[2]; la CNic/ı 986, art. 32; la CPer/ı993, art. 2.24.a.

94 El texto integral de la sentencia puede consultarse en: $<$ http://www.tsj.gov.ve/decisiones/scon/ febrero/I90-280208-03-2630.HTM> (consultado el 24/07/2015).

95 Asimismo, no obstante precisar que la norma constitucional no prohíbe ni condena las uniones de hecho entre personas del mismo sexo, pues ellas encontrarían cobertura en el derecho fundamental al libre desenvolvimiento de la personalidad (art. 20 CVen/I999), se vio obligada a aclarar que, si bien no se les garantiza a las mismas ningún régimen de protección especial o extra (como tampoco se lo hace respecto de las uniones de hecho heterosexuales que no alcancen los requisitos legales para ser consideradas concubinatos), ello no implica que no se les reconozca el disfrute de ciertos derechos, especialmente de los económicos, pero no ya a través del recurso a la noción de la comunidad concubinaria sino al de la comunidad ordinaria de bienes (en los términos en que la legislación civil lo permita). Sin embargo, como señalara la magistrada Carmen Zuleta de Mechán en su voto disidente, la interpretación de la mayoría de la Sala partiría de una falsa premisa, ya que no obstante no prohibir ni condenar las uniones de hecho entre personas de igual sexo se les estaría negando las consecuencias jurídicas del derecho al libre desevolvimiento de la personalidad, al dar por implícito un modelo constitucional de heterosexualidad obligatoria que desconocería los valores del Estado pluralista en los cuales se fundamentó el Estado social de derecho y de justicia que proclama el Preámbulo de la Constitución de la República Bolivariana de Venezuela (cfr. ibíd., p. 20).

96 El texto integral de esta otra sentencia puede verse en: <http://www.tribunalconstitucional. $\mathrm{cl} / \mathrm{wp} /$ expedientes? rol=I $88 \mathrm{I}$ - IO> (consultado el 24/07/20I 5); sobre la cual remitimos, entre otros, a Hernán Corral Talciani, "Tribunal Constitucional y matrimonio homosexual. Comentario a la sentencia rol n. ${ }^{\circ}$ I $88 \mathrm{I}-20 \mathrm{I}$, de 3 de noviembre de $20 \mathrm{I} \mathrm{I}$ ", Revista de Derecho, n. ${ }^{\circ}$ I, Santiago, 20 I I, Universidad de Chile, pp. 25 I ss.; Rodolfo Figueroa G., "El matrimonio ante el Tribunal Constitucional", Anuario de Derecho Público, Santiago de Chile, 20 2, Universidad Diego Portales, pp. I I 7 ss., y Jorge Contesse Singh, "Matrimonio civil y Constitución Política: la sentencia del Tribunal Constitucional sobre matrimonio para parejas del mismo 
inaplicable por inconstitucionalidad el artículo IO2 del CcCh/I857 que exige que el matrimonio sea contraído entre un hombre y una mujer ${ }^{97}$, y ello por considerar que en el ordenamiento constitucional chileno la competencia para decidir qué cosa es el matrimonio y cuáles son sus requisitos y efectos corresponde exclusivamente al Poder Legislativo (art. 63.3 CCh/r98I) ${ }^{98}$, empleando así el modo de razonar típico del "Estado 'legal' de derecho" y no el correspondiente al "Estado 'constitucional' de derecho" (cfr. supra I.A)99.

En cambio, en sentido favorable al reconocimiento de la familia homoparental se ha pronunciado la Corte Constitucional de Colombia en una serie de sentencias dictadas a partir del año $2007^{[\mathrm{roo}]}$, en las que (con base en la omisión legislativa, el déficit de protección, la falta de razonabilidad de las medi-

sexo", Anuario de Derechos Humanos, n. ${ }^{\circ}$ 8, Santiago de Chile, 20 I 2, Universidad de Chile, pp. I 55 ss.

97 En efecto, la sentencia fue motivada por el requerimiento presentado por la Cámara de Apelaciones de Santiago de Chile al Tribunal Constitucional, como medida de mejor resolver, acerca de si debía o no aplicar el artículo IO2 del CcCh/r 855 (que define el matrimonio como el "contrato solemne por el cual un hombre y una mujer se unen actual e indisolublemente, y por toda la vida, con el fin de vivir juntos, de procrear y de auxiliarse mutuamente") para la resolución de un recurso de protección (equivalente a lo que en otros países se denomina amparo constitucional) interpuesto contra las decisiones de un Oficial del Registro Civil de no autorizar la celebración de un matrimonio entre personas del mismo sexo ni de proceder a la inscripción de otros dos matrimonios de parejas del mismo género celebrados en el extranjero (uno en Argentina y el otro en Canadá).

98 Ibíd., pp. 8 s. Además, respecto de las parejas que habían contraído matrimonio en el extranjero, el Tribunal Constitucional chileno consideró que el requerimiento de control de constitucionalidad no había sido formulado correctamente, pues versando la causa sobre casamientos celebrados en el extranjero, la norma decisiva para la resolución del caso no era el artículo Io2 del CcCh/I 855 sino el 80 de la Ley de Matrimonio Civil de 2004 que establece que "el matrimonio celebrado en país extranjero, en conformidad con las leyes del mismo país, producirá en Chile los mismos efectos que si se hubiere celebrado en territorio chileno, siempre que se trate de la unión entre un hombre y una mujer" (cfr. ibíd., pp. Io s.).

99 El único voto disidente fue el del ministro Hernán Vodanovic Schnake (cfr. ibíd., pp. 69 ss.), quien sostuvo que el matrimonio es una construcción social histórica que en el estado actual ha perdido la función relevante de procrear, para tener como objeto expresar fines de solidaridad, afecto y asistencia recíproca, por lo que excluir de sus alcances a las personas del mismo género constituiría una discriminación arbitraria e injustificada incompatible con el respeto de la dignidad humana, la autonomía individual y la igualdad ante la ley, al tiempo que incumple con el mandato constitucional de protección a la familia, entendido en términos amplios (arts. I, 5 y $19.2 \mathrm{CCh} / \mathrm{I} 98 \mathrm{I}-\mathrm{I} 989$ ).

ı०o Cabe señalar que con anterioridad a esta fecha la Corte Constitucional colombiana había resuelto por mayoría de sus integrantes (cfr. sentencias C-098 de 1996, SU-623 de 200 I, C-8 I 4 de 2001 y T-725 de 2004) que el tratamiento desigual dado por el legislador a las parejas heteroxesuales y a las homosexuales no comportaba un trato discriminatorio respecto de las últimas, por considerarse que la familia que protegía la CCol/I 99I (art. 42) era la heterosexual y monogámica (cfr., sobre este particular, Paula Andrea Ceballos Ruiz, Juliana Victoria Ríos Quintero y Richard Marino Ordóñez Patiño, "El reconocimiento de derechos a las parejas del mismo sexo: el camino hacia un concepto de familia pluralista", Estudios Socio-furídicos, n. ${ }^{\circ}$ I4, Bogotá, 20I 2, pp. 2 I 7 ss.). 
das adoptadas bajo el criterio sexo y género, la violación de la igualdad y de la dignidad humana) ${ }^{\text {IOI }}$ se fue extendiendo progresivamente el régimen de las uniones convivenciales heterosexuales a las integradas por personas del mismo género (sentencias C-075 de 2007, C-8I I de 2007, C-336 de 2008, C-798 de 2008, T-9I I de 2009, C-029 de 2009, T-05 I de 2010, C-283 de 20 I I, T-27 6 de 2012 y SU-6I 7 de 20I4) ${ }^{\text {I02 }}$, hasta llegar incluso a reconocérseles -así sea solo indirectamente- la posibilidad de contraer matrimonio (sentencia C-577 de $20 \mathrm{II})^{\mathrm{IO} 3}$. En sentido similar se ha pronunciado la Suprema Corte de Justicia

io Cfr., entre otros, Rosa Elizabeth Guío Camargo, "El concepto de familia en la legislación y en la jurisprudencia de la Corte Constitucional colombiana”, Studiositas, n. ${ }^{\circ}$ 4, Bogotá, 2009, pp. 76 ss.; Quinche Ramírez y Armenta Ariza, ob. cit., pp. 56 ss., y Ceballos Ruiz, Ríos Quintero y Ordóñez Patiño, ob. cit., pp. 207 ss.

IO2 Los derechos y obligaciones reconocidos a las parejas de personas del mismo sexo por estas sentencias son: la constitución de patrimonio familiar inembargable; la garantía de no declarar contra el compañero o la compañera permanente; los derechos migratorios para extranjeros que conviven con un colombiano o colombiana, y de residencia para el compañero o la compañera permanente; la agravación punitiva cuando la víctima del delito fuera compañero o compañera permanente del autor; los derechos a la verdad, a la justicia y a la reparación para los compañeros permanentes de las víctimas de crímenes atroces; las medidas de protección civil a favor de las víctimas de crímenes atroces; la administración de los bienes de personas víctimas de desaparición forzada y protección de las víctimas del secuestro; la pensión de sobrevivencia y la afiliación al sistema de salud de los miembros de las Fuerzas Militares y la Policía Nacional; las normas penales y preventivas de delitos que tienen por sujeto pasivo al compañero o la compañera permanente: la inasistencia alimenticia, la malversación y dilapidación de bienes de familiares, la violencia intrafamiliar; el subsidio familiar en servicios y para vivienda; el derecho al acceso progresivo a la propiedad de la tierra de los trabajadores agrarios, la protección de la función social de la propiedad y el derecho al crédito del trabajador agrario; el derecho del compañero o compañera permanente a ser beneficiario de las indemnizaciones del seguro por muerte en accidentes de tránsito; las inhabilidades de los compañeros y compañeras permanentes de los diputados y concejales; las prohibiciones a los compañeros y compañeras permanentes de gobernadores, alcaldes, concejales y diputados; las inhabilidades e incompatibilidades para contratar con el Estado; el derecho de la compañera o compañero sobreviviente a obtener una pensión por viudez; el derecho de adopción del padre soltero o de la madre soltera homosexual; el derecho de adoptar el hijo o la hija del compañero o compañera; entre otros posibles (cfr., en este sentido, Marco Navarro, ob. cit., pp. i9 s. y Ceballos Ruiz, Ríos Quintero y Ordóñez Patiño, ob. cit., pp. 2 I 5 ss.). (Los textos integrales de las referidas sentencias pueden ser consultados en el sitio de la Corte Constitucional colombiana: <http:// www.corteconstitucional.gov.co>).

I03 Solo a partir de este pronunciamiento la Corte Constitucional colombiana reconoció el estatus de familia a las parejas formadas por personas del mismo sexo, al considerar que la misma no se funda en el género o en la consaguinidad sino en los lazos de amor, respeto, solidaridad, ayuda mutua y socorro, lazos de afecto que "constituyen el común denominador de todo tipo de familia" (como, p. ej., la que integran los tíos con sus sobrinos a cargo, los abuelos responsables de sus nietos, la madre o el padre cabeza de familia con sus hijos biológicos o no); de ahí que, "existiendo [estos lazos de afecto] entre los miembros de la pareja homosexual que convive con vocación de permanencia, ha de conluirse que estas parejas también forman una familia que, como las demás, es institución básica y núcleo fundamental de la sociedad y merece la protección de la sociedad misma y del Estado" (cfr. <http://www.corteconstitucional.gov.co/ relatoria/2OI I/c-577-I r.htm> [consultado el 24/07/20I 5], consideración jurídica n. ${ }^{\circ} 4 \cdot 4 \cdot 3 \cdot 2$, p. I60). En honor a la verdad, la Corte solo declaró exequible la expresión "un hombre y una mujer" 
de México en una sentencia del i6/o8/20 Io en la que se rechazó un pedido de inconstitucionalidad de la reforma introducida en 2009 al artículo I 46 del CcMéxDF/ı 928 con la que se configuró el matrimonio como "la unión libre de dos personas" (eliminando así la referencia al requisito de la diversidad de sexo de los contrayentes contenida en el texto en su versión original), al considerarse que la medida legislativa impugnada era válida constitucional y legalmente por no contravenir la CMéx/r9i 7, en atención a que con dicha configuración no se afecta el núcleo esencial ni de la institución matrimonial ${ }^{104}$, ni de la familiar (no estando protegida constitucionalmente, como modelo único e ideal, solo la familia conformada por la unión entre un hombre y una mujer) ${ }^{\mathrm{I0}}{ }^{\text {. En términos }}$

empleada en la definición de matrimonio contenida en el artículo i I 3 del CcCol/1 859 - I 887 (=art. IO2 del CcCh/I855), exhortando luego al Congreso de la República (como ya había hecho en la sentencia C-283 de 20II) para que legisle, antes del 20 de junio de 20 I $_{3}$, "de manera sistemática y organizada", sobre los derechos de las parejas del mismo sexo con la finalidad de eliminar el déficit de protección que afectaba a las mismas, bajo apercibimiento de que si a la fecha indicada no se había expedido la legislación correspondiente "las parejas del mismo sexo podrán acudir ante notario o juez competente a formalizar y solemnizar su vínculo contractual" (ibíd., pp. I92 s.). Todo ello en atención a que si bien la CCol/ragr solo menciona el matrinomio heterosexual y nada dice respecto de las uniones entre personas del mismo género, también es cierto que "no hay un texto expreso que sirva de soporte a la pretendida prohibición de establecer una figura o institución que formalice la unión de la pareja homosexual haciendo de ella un vínculo jurídico constitutivo de familia" (ibíd., consideración jurídica n. ${ }^{\circ} 4 \cdot 5 \cdot 3 \cdot 2$, p. I 77). Fue así que transcurrido el término fijado en la sentencia y, ante la inacción del legislador, se terminó dando cumplimiento al punto resolutivo quinto de la misma, posibilitando en consecuancia la celebración del matrimonio entre personas del mismo género. Sobre esta sentencia remitimos, una vez más, a Quinche Ramírez y Armenta Ariza, ob. cit., pp. 6o s. y Ceballos Ruiz, Ríos Quintero y Ordóñez Patiño, ob. cit., pp. 232 ss.

I04 La sentencia (cuyo texto integral puede consultarse en: <www2.scjn.gob.mx/juridica/engroses/ cerrados/207/10000020.019.doc> [consultado el 24/07/2015]) precisa además que la institución del matrimonio civil ha cambiado con el tiempo, ya que si bien tradicionalmente fue entendida como la unión de un hombre y una mujer para la procreación, en la actualidad esta no se considera una condición absoluta para su validez, en atención a que existen parejas unidas en matrimonio que no desean procrear o no pueden hacerlo (por lo que deciden adoptar o acudir a la reproducción asistida), y por esta razón el matrimonio que las une no sería nulo (cfr. Rosas Martínez, ob. cit., p. I92 s.). Este criterio fue reiterado recientemente por la Primera Sala de la Suprema Corte de Justicia mexicana al resolver en fecha 23/04/2014 el amparo (colectivo) en revisión $\mathrm{I}_{52} / 20 \mathrm{I} 3$, declarando la inconstitucionalidad por discriminatorio del artículo $\mathrm{I} 43$ del Código Civil de Oaxaca que definía al matrimonio como un contrato entre "un solo hombre y una sola mujer", y que tiene por objeto "perpetuar la especie" (respecto del cual ya se había pronunciado en los amparos 457/2012, 567/20I 2 y 58I/20I2); precisando además que si bien es incuestionable que los Congresos estatales tienen libertad de configuración para regular el estado civil de las personas, esta "se encuentra limitada por los mandatos constitucionales y el reconocimiento de derechos humanos desde la Constitución y los tratados internacionales suscritos por México, de conformidad con el artículo I constitucional" (cfr. <http://www2.scjn. gob.mx/ConsultaTematica/PaginasPub/DetallePub.aspx?AsuntoID $=150476>$ [consultado el 24/07/2015], párr. I96, pp. 70 s. y nota 75, donde se cita en apoyo la sentencia C-577 de 20 I I de la Corte Constitucional de Colombia de la que nos ocupamos supra, nota Ioo).

I05 En efecto, como la misma sentencia aclara, si bien la CMéx/r 9 I 7 no contempla expresamente el derecho a contraer matrimonio, en el ordenamiento jurídico mexicano la dignidad humana comprende el derecho al desarrollo de la personalidad, es decir, el derecho de la persona a 
parecidos se ha pronunciado también el Supremo Tribunal Federal de Brasil en una sentencia del 5/05/20 I I ${ }^{[106]}$ por la que unánimemente se decidió aplicar la técnica de la "interpretação conforme à Constituição" al artículo I 723 del Cc$\mathrm{Bra} / 2002$ (que solo califica como "entidade familiar a união estável entre o homem e a mulher"), con la finalidad de excluir del mismo todo significado que impida el reconocimiento de la "união contínua, pública e duradoura entre pessoas do mesmo sexo como família [...] segundo as mesmas regras e com as mesmas consequências da união estável heteroafetiva" ${ }^{\circ 07}$, en consonancia con el artículo 3.Iv de la CBra/I 988 según el cual "Constituem objetivos fundamentais da República Federativa do Brasil: [...] promover o bem de todos, sem preconceitos de origem, raça, sexo, cor, idade e quaisquer outras formas de discriminação" ${ }^{\text {I08. }}$.

elegir de manera libre y autónoma cómo vivir su vida y todo lo que esto supone, entre lo que se ecuentra también la libertad de casarse o no, además de la libertad de procrear hijos, la libertad de decidir cuántos hijos procrear o bien de no tenerlos, la libertad de elegir la apariencia personal y la libre opción sexual (la que a su vez abarca la libre preferencia sexual); todo lo cual impone al Estado el deber de reconocer la posibilidad de que las personas del mismo género puedan elegir libremente estar unidas entre sí por el concubinato, por la "sociedad de convivencia" (reconocida legalmente en el Distrito Federal en 2006 y sucesivamente en otras entidades federativas mexicanas) o directamente por el matrimonio (cfr., de nuevo, Rosas Martínez, ob. cit., pp. I 94 s.).

ıо6 Cfr. el texto integral de este Acórdão del Supremo Tribunal Federal brasileño, en el que se resolvieron conjuntamente la Arguição de Descumprimento de Preceito Fundamental-ADPF n. ${ }^{\circ}$ I32/RJ y la Ação Direta de Inconstitucionalidade-ADI n. ${ }^{\circ} 4.277 / \mathrm{DF}$, en: <http://redir.stf.jus.br/ paginadorpub/paginador.jsp? docTP=AC\&docID=628635> (consultado el 24/07/201 5).

io7 Cfr. Rel. del Min. Ayres Britto (ibíd., párr. 50, p. 656). Asimismo, al analizar las diferentes disposiciones constitucionales que tratan sobre la familia, el Ministro relator concluye que las mismas no hacen ninguna distinción entre la familia "formalmente constituida" y la "existente ao rés dos fatos", así como tampoco entre la familia formada por "sujeitos heteroafetivos" y la constituida por "pessoas de inclinação homoafetiva", al no otorgarle al sustantivo "família" ningún significado ortodoxo; en efecto, la CBra/I 988 "recolheu-o com o sentido coloquial praticamente aberto que sempre portou como realidade do mundo do ser" (ibíd., párr. 46, p. 648).

Io8 Es de destacar además que, en atención a que la Ley 9.278 de 1996 (que regula en detalle la "união estável") dispone en su artículo 8 que "Os conviventes poderão, de comum acordo e a qualquer tempo, requerer a conversão da união estável em casamento, por requerimento ao Oficial do Registro Civil da Circunscrição de seu domicílio", muchas uniones estables entre personas del mismo género fueron convertidas en matrimonios. La validez del matrimonio "homoafectivo" fue reconocida luego por una sentencia de la Sala Cuarta del Superior Tribunal de Justicia de Brasil del $25 / 10 / 20$ I I (cfr. supra, nota 36 ), en la que se interpretó que "os arts. I.5 I4, I.52 I, I.523, I.535 e 1.565 [...] do Código Civil de 2002, não vedam expressamente o casamento entre pessoas do mesmo sexo" (ni siquiera cuando emplean los términos "homem" y "mulher" o la expresión "marido e mulher"), y que "não há como se enxergar uma vedação implícita ao casamento homoafetivo sem afronta a caros princípios constitucionais, como o da igualdade, o da não discriminação, o da dignidade da pessoa bumana e os do pluralismo e livre planejamento familiar" (cfr. Acórdão del Recurso Especial-REsp n . I.I83.378/Rs, Rel. del Min. Luis Felipe Salomão, en <http://www.mpsp.mp.br/portal/ page/portal/Civel_Geral/Registros_Publicos/Jurisprudencia_registros/stJ-\% 20 REsp $\% 20$

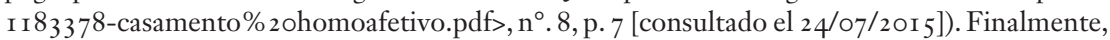
el I $4 / 05 / 2013$ el Consejo Nacional de Justicia brasileño aprobó la Resolución n. ${ }^{\circ}$ I 75 por la cual se obligó a los notarios de todo el país a convertir las uniones estables entre personas del mismo género en matrimonio. 
Asimismo cabe recordar aquí que a favor de la familia homoparental se ha expresado también -así sea solo tangencialmente- la Corte Interamericana de Derechos Humanos en la sentencia dictada el 24/02/20 2 en el caso "Atala Riffo y niñas vs. Chile", al reconocer que la misma es objeto de protección por parte de la Convención Interamericana sobre Derechos Humanos de ig69 en lo que respecta a los derechos a la igualdad y no discriminación (art. I.I), a la vida privada (art. I I.2) y al derecho reconocido a todos los hombres y a todas las mujeres de fundar una familia (art. 17.2) ${ }^{\text {I09. }}$

\section{La familia monoparental}

La familia monoparental es aquella constituida por uno solo de los progenitores y sus descendientes, a la que se puede acceder de manera originaria, en aquellos ordenamientos latinoamericanos que admiten el empleo de las técnicas de reproducción asistida y/o la adopción por parte de personas solteras, o en forma derivada, como resultado de la extinción de una unión matrimonial o convivencial precedente, sin que el progenitor que se ha hecho cargo de los hijos haya vuelto a formar una nueva pareja (cfr. infra II.E).

Este otro modelo familiar ha merecido ya la atención explícita de algunas Cartas constitucionales latinoamericanas, las cuales se encargan de garantizar una protección especial para la misma dada su condición de vulnerabilidad ${ }^{\text {I }}$, ya sea que limiten la tutela solo a aquellos casos más comunes en los cuales es la mujer la jefa de familia ${ }^{\text {II }}$, o que la reconozcan en forma amplia y con independencia del género del o de la cabeza de familia ${ }^{\mathrm{II} 2}$.

Es precisamente la vulnerabilidad que generalmente caracteriza a esta tipología familiar la que justificó la solución adoptada por la Corte Suprema de Justicia de la Nación Argentina en su sentencia del 24/04/20 I 2 , en la causa "Q. C., S. Y. c/ Gobierno de la Ciudad de Buenos Aires s/ Amparo" ${ }^{113}$, por la que se

Io9 Cfr., en este sentido, <http://www.corteidh.or.cr/docs/casos/articulos/seriec_239_esp.pdf>, párrs. I 77 y 222 y pp. 57 y 70 (consultado el 24/o7/201 5), y Llaja Villena y Ramírez HuaroTo, ob. cit., pp. 327 s.

I ro Es por ello que en algunos ordenamientos se intenta incluso eliminar la principal causa de esta última fattispecie de familia estableciendo, como regla, la custodia compartida de la prole después del divorcio o de la disolución de la unión convivencial (cfr., en este sentido, Kemelmajer De CARLUCCI, Las nuevas realidades familiares en el Proyecto de Código civil y comercial argentino cit., p. I20).

i I I Cfr., p. ej., la CCol/ı99i, art. 43[2]; la CPar/ı 992, arts. 53[3] y i I 5.9.

i 2 Cfr., p. ej., la CBra/ı 988, art. 226.4; la CPar/ı 992, art. 49i.f; la Ven/ı999, art. 75[r]; la CEcu/2008, art. 69.4. La Corte Constitucional colombiana ha extendido la protección al hombre que se encuentra en la misma condición de una mujer cabeza de familia (cfr. sentencias C-964 de 2003, C-r 84 de 2003 y C-044 de 2004).

I $3 \mathrm{El}$ texto integral de la sentencia puede leerse en: <http://www.csjn.gov.ar/jurisp/jsp/fallos.do ?usecase $=$ mostrarDocumento\&falloId $=5878>$ (consultado el $24 / 07 / 2015)$, y sobre la misma 
condenó al Gobierno de la Ciudad Autónoma de Buenos Aires a garantizar el derecho a la vivienda a una mujer cabeza de familia y a su hijo menor de edad discapacitado (para preservar la integridad familiar de los mismos) ${ }^{\mathrm{II}}{ }^{4}$, ordenándole que: i) "provea a la actora del asesoramiento y la orientación necesarios para la solución de las causas de su problemática habitacional", y ii) "garantice a la actora, aun en forma no definitiva, un alojamiento con condiciones edilicias adecuadas a la patología que presenta el niño, sin perjuicio de completar su inclusión en algún programa de vivienda en curso o futuro para la solución de la situación de excepcional necesidad planteada" ${ }^{15}$.

\section{E. La familia ensamblada}

La familia ensamblada es aquella en la que uno o ambos integrantes de la pareja aportan al nuevo núcleo familiar hijos de otras uniones precedentes (matrimoniales o convivenciales) o de una familia monoparental originaria (cfr. supra II.D), de ahí la necesidad de regular las relaciones que se podrían establecer respectivamente entre cada uno de los cónyuges o convivientes y los hijos del otro. Se trata de un modelo familiar que ha comenzado a ser reconocido por algunos ordenamientos jurídicos latinoamericanos ${ }^{116}$, si bien la mayor parte de estos aún no ha abordado sistemáticamente su complejidad ${ }^{117}$.

remitimos también a Kemelmajer de Carlucci, Las nuevas realidades familiares en el Proyecto de Código civil y comercial argentino cit., pp. I I 9 ss.

I 4 La sentencia se fundó en el artículo I4 bis de la CArg/I853-I957 (tributario en este punto del art. $37 \mathrm{CArg} / \mathrm{r} 949$ ), que prevé que la ley establecerá "el acceso a una vivienda digna"; en el artículo 75, inciso 23, de la CArg/ı 853-I957-1994, que refuerza el citado mandato constitucional de tutela en situaciones de vulnerabilidad al disponer que el Congreso debe "legislar y promover medidas de acción positiva que garanticen (...) el pleno goce y ejercicio de los derechos reconocidos por esta Constitución y por los tratados vigentes sobre derechos humanos, en particular respecto de los niños (...) y las personas con discapacidad"; y, por este reenvío, en los artículos 25 de la Declaración Universal de Derechos Humanos de I948, i I. I del Pacto Internacional de Derechos Económicos, Sociales y Culturales de i966, xi de la Declaración Americana de los Derechos y Deberes del Hombre de 1948, 23, 24, 27. I y 3 de la Convención sobre los Derechos del Niño de I989, y 7.I y 2 de la Convención sobre los Derechos de las Personas con Discapacidad de 2006 (cfr. ibíd., considerando 8, pp. 8 ss.).

I 5 Todo ello en atención a que "los derechos fundamentales que consagran obligaciones de hacer a cargo del Estado con operatividad derivada, están sujetos al control de razonabilidad por parte del Poder Judicial", lo que "significa que, sin perjuicio de las decisiones políticas discrecionales, los poderes deben atender a las garantías mínimas indispensables para que una persona sea considerada como tal en situaciones de extrema vulnerabilidad" (cfr. ibíd., considerando I 7 , p. 29).

i 6 Como hace, p. ej., el nuevo Código Civil y Comercial argentino de 20 I 4 que regula los "Deberes y derechos de los progenitores e hijos afines" (arts. 672-676) y la denominada "adopción de integración" (arts. 630-633); sobre lo cual remitimos, nuevamente, a Kemelmajer De Carlucci, Las nuevas realidades familiares en el Proyecto de Código civil y comercial argentino cit., pp. I I 3 ss.

i 7 Como observa, entre otros, Marco Navarro, ob. cit., p. i i. 
Sobre este particular resulta de interés una sentencia de la Sala Primera del Tribunal Constitucional peruano, dictada el 30/06/2007 en el Exp. 093322006-PA/TC ${ }^{118}$, en la que se hizo lugar a una demanda de amparo contra la decisión de una asociación recreativa que se había negado a expedir a la hija de la esposa de uno de sus socios el carné de familiar, otorgándole en cambio a la menor un mero pase de invitada especial (renovable anualmente hasta los venticinco años), por considerar que dicha medida era discriminatoria y lesiva del derecho a la igualdad de los hijos (en este caso de los afines respecto de los biológicos) y del derecho a fundar una familia (reconocidos ambos por los arts. 4 y 6 [3] CPer/I993, i6 de la Declaración Universal de los Derechos Humanos del I948, 23 del Pacto Internacional de Derechos Civiles y Políticos de I 966 y 17 de la Convención Americana sobre Derechos Humanos de 1969) ${ }^{\text {I19. }}$. Así, mediante la citada sentencia el Tribunal Constitucional peruano estableció que el hijo y el padre afín integran una estructura familiar, con eventuales derechos y deberes especiales (lo que no implica la pérdida de la patria potetad por parte de los padres biológicos), y que no reconocer esto traería aparejada una afectación a la identidad del nuevo núcleo familiar, lo que de hecho contraría lo dispuesto por la Carta fundamental respecto de la protección que merece la familia como instituto jurídico constitucionalmente garantizado ${ }^{120}$.

En igual sentido puede citarse la sentencia T-606 de 2013 de la Corte Constitucional de Colombia que ordenó a una empresa reconocerle a la hija de la conviviente de uno de sus trabajadores iguales derechos que los que gozaba la

I 8 Cfr. el texto integral de la sentencia en: <http://www.tc.gob.pe/jurisprudencia/2008/o93322006-AA.html> (consultado el 24/07/2015). Sobre la misma remitimos, en general, a PAUla Severino Bavio, "Apuntes de la sentencia del tc sobre familias ensambladas. Una lectura posible de la sentencia del Tribunal Constitucional peruano en el caso Scholz Pérez", en Ius (Furisprudencia), 3, Lima, 2008, pp. 66 ss., y Yuri Vera Mere, "La ampliación del Derecho de Familia por obra del Tribunal Constitucional. A propósito de la incorporación de la familia ensamblada y de la concesión de mayores derechos a la familia de hecho", Gaceta del Tribunal Constitucional, n. ${ }^{\circ}$ Io, Lima, abril-junio de 2008, pp. 3 ss.

I 9 En el mismo sentido se ha expresado el Pleno del Tribunal Constitucional peruano en la sentencia dictada el 30/06/2010 en el Exp. 04493-2008-pa/Tc, en la que se precisa además que "debe tomarse en cuenta que los acelerados cambios sociales pueden generar una brecha entre la realidad y la legislación, provocando vacíos en el ordenamiento jurídico. En tal sentido, frente a conflictos intersubjetivos que versen sobre las nuevas estructuras familiares, los jueces tendrán que aplicar los principios constitucionales a fin de resolverlos, interpretando la legislación también en función de la realidad, y por consiguiente brindando la paz social que es tarea prevalente del derecho" (cfr. <http://www.tc.gob.pe/jurisprudencia/201o/o44932008-AA.html>, fundamentos 1 7-22 [consultado el 24/07/2015]).

I 20 Ibíd., fundamento i r. Más adelante, en la misma sentencia, se afirma además: "Cabe anotar que por las propias experiencias vividas por los integrantes de este nuevo núcleo familiar-divorcio o fallecimiento de uno de los progenitores- la nueva identidad familiar resulta ser más frágil y difícil de materializar. Es por ello que realizar una comparación entre el hijo afín y los hijos [biológicos] debilita la institución familiar, lo cual atenta contra lo dispuesto en el artículo 4 de la Constitución, según el cual la comunidad y el Estado protegen a la familia" (ibíd., fundamento I4). 
hija biológica de este, por considerar que la negativa del empleador a inscribir a la menor en el correspondiente régimen de salud argumentando que no era hija de su dependiente vulneraba los derechos a la seguridad social (arts. $44 \mathrm{y}$ 48), a la protección integral de la familia (art. 42 [2]) y a la igualdad (art. I3) reconocidos por la CCol/r $99 \mathrm{I}$. La Corte consideró igualmente lesivo de dichas garantías imponer al trabajador la adopción de la niña, como había sugerido la empresa, pues ello implicaría para la menor renunciar a la filiación con la familia de su padre biológico ya fallecido ${ }^{\mathrm{I2}}$. Es que, como bien concluye la Corte colombiana, exigir en este tipo de casos la existencia de vínculos naturales o jurídicos supone ignorar la segregación que podría generarse en las familias ensambladas, así como también la evolución y dinámica de las relaciones humanas en la actualidad; lo anterior hace imperioso reconocer que existen núcleos y relaciones familiares en donde las personas están unidas única y exclusivamente por situaciones de facto "caracterizadas y conformadas a partir de la convivencia y en virtud de los lazos de afecto ${ }^{\mathrm{I} 22}$, solidaridad, respeto, protección y asistencia, y en las cuales puede identificarse como padres o abuelos de crianza a los cuidadores que ejercen la autoridad parental, relaciones familiares de crianza que también son destinatarias de las medidas de protección a la familia fijadas en la Constitucional Política y la ley" ${ }^{223}$.

\section{F. La familia ampliada}

La familia ampliada, es decir la compuesta no solo por el núcleo familiar formado por los padres e hijos sino extendida también a los ascendientes e -incluso- a otros parientes o personas, ha sido reconocida también más o menos explícitamente por algunas Constituciones latinoamericanas al imponer a la familia (conjuntamente con el Estado y la Sociedad) el cuidado de los ancianos, así como también de las personas adultas con capacidad diferente ${ }^{\mathrm{I2}}$.

I 2 I El texto integral de la sentencia puede consultarse en <http://www.corteconstitucional.gov. co/relatoria/2013/t-606-I 3.htm> (consultado el 24/07/2015).

I 22 La sentencia analizada parecería referir aquí al denominado "parentesco social afectivo", es decir al que se funda no ya en lazos bilógico o genéticos sino en el afecto, noción esta que, originada en el derecho brasileño (a afetividade), se ha comenzado a extender también a otros ordenamientos latinoamericanos (p. ej., el nuevo Código Civil y Comercial argentino de 2014, que la recoge en los arts. 59 y 556). Sobre la apertura al "afecto" como concepto jurídico cfr., entre otros, Maria Berenice Dias, Eliene Ferreira Bastos y Naime Márcio Martins Moraes (coords.), Afetos e estruturas familiares, Belo Horizonte, zo io, passim, y Marisa Herrera, "La noción de socioafectividad como elemento "rupturista" del derecho de familia contemporáneo", Derecho de Familia. Revista Interdisciplinaria de Doctrina y furisprudencia, n. ${ }^{\circ} 66$, Buenos Aires, pp. 75 ss.

I 23 De esta manera la Corte Constitucional colombiana reafirmó y consolidó el concepto pluralista de familia que adoptara en la sentencia C-577 de 20 I I (cfr. supra, nota Ioo).

I24 Cfr., p. ej., la CNic/ı986, art. 77; la CCol/ı99ı, art. 46; la CPar/ı992, art. 57; la CVen/ı999, arts. 80 y $8 \mathrm{I}$. 
Se trata, sin embargo, de disposiciones que hacen referencia a aspectos más vinculados con la seguridad social y que muchas Constituciones de la segunda generación ponían solo a cargo del Estado, mientras que las vigentes colocan también -aunque generalmente con carácter subsidiario- a cargo de las familias, lo que significa que en la mayoría de los casos el referido deber terminará recayendo directamente sobre ellas y que, dentro de las mismas, lo hará sobre las mujeres (agravando aún más su condición de vulnerabilidad) ${ }^{125}$.

Sin embargo, algunos ordenamientos latinoamericanos han comenzado a regular en sus respectivas legislaciones secundarias cuestiones de otra naturaleza, como es el caso del deber impuesto a los progenitores de respetar y facilitar el derecho del hijo a mantener relaciones personales con abuelos, otros parientes o personas con las cuales tenga un vínculo afectivo ${ }^{\mathrm{I} 26}$.

A este modelo familiar hace referencia también, expresamente, la Convención sobre los Derechos del Niño de I989 cuando en su artículo 5 impone a los Estados la obligación de respetar las responsabilidades, derechos y deberes que respecto del menor tengan no solo los padres sino también, entre otros, los miembros de la "familia ampliada".

\section{G. La familia indígena}

Esta última tipología familiar no se encuentra expresamente reconocida por las Constituciones latinoamericanas, aun cuando su admisión se desprendería de las disposiciones contenidas en la mayor parte de los textos constitucionales vigentes en los que se reconoce a los pueblos indígenas -entre otras cosas- el derecho a regirse por sus propias costumbres, tradiciones y organización social, siempre que las mismas sean compatibles con los derechos fundamentales previstos por el ordenamiento jurídico nacional y con los derechos humanos reconocidos internacionalmente ${ }^{127}$; lo que se encuentra en sintonía con el Convenio n. ${ }^{\circ}$ I69 de la Organización Internacional del Trabajo sobre Pueblos Indígenas y Tribales en Países Independientes de I989, ratificado casi unánimemente en la Región (cfr. supra I.в).

No obstante lo anterior, la mayor parte de los ordenamientos de América Latina no han desarrollado con suficiencia el referido mandato constitucional

I 25 Tal como hace notar Marco Navarro, ob. cit., pp. 9 s.

I 26 Así, a mero título ejemplificativo, puede citarse en este sentido el nuevo Código Civil y Comercial argentino de 2014 (art. 646.e).

I 27 Cfr., p. ej., la CPan/ı972, art. 90; la CNic/ı 986, art. 5[3]; la CBra/ı988, art. 23 I; la CMéx/I9I7-I992, art. 2; la CPar/I992, art. 63; la CGua/ı993, art. 66; la CArg/1853-I994, art. 75. I 7; la CVen/ı 999, art. I i 9; la CEcu/2008, art. 57.I, 9 y I 9; la CBol/2009, art. 30.11 .2 y 5. Las mismas garantías han sido extendidas también, por algunas de las Constituciones latinoamericanas más recientes, a los grupos de orígen africano (cfr., p. ej., CEcu/2008, art. 58, y $\mathrm{CBol} / 2009$, art. 32). 
en lo que respecta al derecho de familia, salvo contadas excepciones, como son: i) el Código de la Familia de Bolivia de I972, que aun antes del desarrollo del neoconstitucionalismo latinoamericano había reconocido las "Formas prematrimoniales indígenas y otras uniones de hecho" (art. I60) contempladas en las costumbres de las "naciones y pueblos indígenas originarios campesinos", como es el caso del tantanacu o sirvinacu (una especie de "matrimonio a prueba") ${ }^{\mathrm{I} 28}$, para cuya regulación se tienen en cuenta "los usos y hábitos locales o regionales siempre que no sean contrarios a la organización esencial de la familia" establecida por el mismo Código, o que "no afecten al orden público y a las buenas costumbres"I29; ii) el Código de la Familia de Panamá de i994, que reglamenta el matrimonio de los kunas en la Comarca de San Blas (arts. 60-66), cuya celebración "se inicia con el desarrollo de las ritualidades tradicionales de dicha Comarca en acto público, y culmina con la comparecencia de los contrayentes ante el Sáhila [jefe político-religioso de la comunidad] y su secretario, o quien haga sus veces, y por lo menos, ante dos testigos mayores de edad" (arts. 63 y 64), debiéndose inscribir el acto en el libro de matrimonios de la Dirección Comarcal del Registro Civil (art. 66) ${ }^{\mathrm{I}}{ }^{\circ}$.

\section{Conclusiones}

Con base en lo hasta aquí analizado puede concluirse que:

a) El particular interés demostrado por las Constituciones de la América Latina en regular de manera especial y en forma detallada las relaciones familiares constituye una característica del Subsistema jurídico latinoamericano (en cuanto desarrollo interno propio del Sistema jurídico romanístico), en el cual la "unidad social" es la familia y no el individuo aislado) (como sucede en otras experiencias jurídicas, tales como la del common law).

b) Esta característica, que estaba ya presente en el constitucionalismo social latinoamericano pero en modo más bien programático, fue conservada e incluso hecha efectiva por el neoconstitucionalismo que se desarrolló en

I 2 Cfr., entre otros, Hugo Connejo Chávez, "El servinakuy", Roma e America. Diritto romano comune, vol. 27, Módena-Bogotá, 2009, pp. 277 Ss. (<www.romaeamerica.it>).

I 29 Estas figuras no se encuentran contempladas en el reciente Anteproyecto de Código de las Familias y del Proceso Familiar del Estado Plurinacional de Bolivia de 20r3, el cual sin embago prevé que las formalidades de la celebración del matrimonio puedan "articularse a otros ritos, usos y costumbres, observándose que esta celebración cumpla su finalidad” (en sentido similar a lo previsto por los arts. 63 y 67 del Código de la Familia de Panamá de r 994).

I 30 El mismo Código establece que "los otros grupos indígenas de la Nación podrán solicitar el reconocimiento civil para los matrimonios que se celebren conforme a sus respectivas tradiciones, y a ese efecto, deberán comprobar la existencia de sus tradiciones" (art. 67). 
la Región a partir de los años ochenta del siglo pasado, al considerarse la Constitución (así como también los tratados internacionales sobre derechos humanos con jerarquía constitucional) como un mandato directo del poder constituyente al poder constituido, cuya resultante es la "constitucionalización" e "internacionalización" de todo el ordenamiento jurídico.

c) La dinámica de estos dos procesos sucesivos y convergentes, guiada en gran parte por la labor sinérgica llevada a cabo por los órganos nacionales con competencia para efectuar los controles de constitucionalidad y de convencionalidad y por los organismos supranacionales encargados de interpretar y aplicar los instrumentos internacionales sobre derechos humanos, ha incidido directa y profundamente sobre el concepto mismo de familia al imponer una relectura de las relaciones familiares a la luz de los derechos fundamentales.

d) Como consecuencia de este nuevo paradigma constitucional se constata que en la mayor parte de los ordenamientos de Latinoamérica, aunque con diferentes matices, se ha pasado: i) de un modelo de familia "totalizante" a otro más "democrático", donde se trata de conciliar el interés familiar con el interés personal de sus integrantes (sobre todo de aquellos más vulnerables), y ii) de un modelo "único" de familia al reconocimiento de una "pluralidad" de modelos familiares, todos ellos dignos de igual tutela (como pueden ser, p. ej., la familia matrimonial, la convivencial, la homoparental, la monoparental, la ensamblada, la ampliada, la indígena, etc.).

\section{Bibliografía}

Alfonso, César, "La obligatoriedad de las decisiones de la Corte Interamericana de Derechos Humanos desde la perspectiva de distintos países de América del Sur", en Kai Аmbos, Ezequiel Malarino y Gisela Elsner (coords.), Sistema Interamericano de Protección de los Derechos Humanos y Derecho penal internacional, Montevideo, 2010 , pp. 63 ss.

Bidart Campos, Germán, "El derecho de familia desde el derecho de la Constitución", Revista "Entre abogados", Foro de Abogados de San Juan, año iv, n. ${ }^{\circ}$ 2, San Juan (Argentina), I998, pp. I 7 ss.

Brewer-Carías, Allan R., "La aplicación de los Tratados internacionales sobre Derechos Humanos en el orden interno de los países de América Latina", Revista del Instituto Interamericano de Derechos Humanos, vol. 46, San José de Costa Rica, 2007, pp. 2 I 9 ss.

Carbonell, Miguel; Sandra Moguel y Karla Pérez Portillo (comps.), Derecho Internacional de los Derechos Humanos. Textos básicos, t. I, México, D.F., 2003. 
Carbonell, Miguel, "Familia, constitución y derechos fundamentales", en Rosa María Álvarez de Lara (coord.), Panorama internacional de Derecho de Familia. Culturas y sistemas jurídicos comparados, t. I, México, D.F., 2006, pp. 8 I ss.

Castañeda Otsu, Susana, "El principio de interpretación conforme a los Tratados de Derechos Humanos y su importancia en la defensa de los derechos consagrados en la Constitución”, en Ricardo Méndez Silva (coord.), Derecho internacional de los Derechos Humanos. Memoria del VII Congreso iberoamericano de Derecho constitucional, México, D.F., 2002, pp. 2 I I ss.

Catalano, Pierangelo, Diritto e persone, Torino, i99o.

Catalano, Pierangelo, "Sistema y ordenamientos: el ejemplo de América Latina”, Roma e America. Diritto romano comune, vol. I 8, Módena-Bogotá, 2004, pp. 30 ss. (<www.romaeamerica.it>).

Chávez Asencio, Manuel, La familia en el derecho: derecho de familia y relaciones jurídicas familiares, México, D.F., I 984.

Chávez Asencio, Manuel, "Alternativas constitucionales para la familia del siglo xxi”, Revista Mexicana de la Procuración de fusticia, vol. I, México, D.F., I 997 , pp. I I 3 ss.

Chávez Hernández, Efrén, "La protección constitucional de la familia. Una aproximación a las Constituciones latinoamericanas", en Rosa María ÁlvaREZ De Lara (coord.), Panorama internacional de Derecho de Familia. Culturas y sistemas jurídicos comparados, t. I, México, D.F., 2006, pp. I 28 ss.

Chía, Eduardo y Contreras, Pablo, "Análisis de la sentencia 'Artavia Murillo y otros ('Fecundación in vitro') vs. Costa Rica' de la Corte Interamericana de Derechos Humanos", en Estudios Constitucionales, año I 2, n. $^{\circ}$ I, Santiago de Chile, 20i4, pp. 567 ss.

Ciuro Caldani, Miguel Ángel, "Filosofía del Derecho de Familia”, Investigación y Docencia, vol. 34, Rosario, 200 I, pp. I 5 ss.

Ciuro Caldani, Miguel Ángel, “Aportes de la Filosofía del Dereho al Derecho de Familia”, Investigación y Docencia, vol. 48, Rosario, 2014 , pp. I 3 ss.

Ceballos Ruiz, Paula Andrea; Juliana Victoria Ríos Quintero y Richard Marino Ordóñez Patiño, "El reconocimiento de derechos a las parejas del mismo sexo: el camino hacia un concepto de familia pluralista”, Estudios Socio-furídicos, n. ${ }^{\circ}$ I 4, Bogotá, 2012 , pp. 2 I 7 ss.

Contesse Singh, Jorge, "Matrimonio civil y Constitución Política: la sentencia del Tribunal Constitucional sobre matrimonio para parejas del mismo sexo", Anuario de Derechos Humanos, n. ${ }^{\circ}$ 8, Santiago de Chile, 20 I 2, Universidad de Chile, pp. I 55 ss.

Cornejo Chávez, Hugo, "El servinakuy", Roma e America. Diritto romano comune, vol. 27, Módena-Bogotá, 2009, pp. 277 ss. 
Corral Talciani, Hernán, "Tribunal constitucional y matrimonio homosexual. Comentario a la sentencia rol n. ${ }^{\circ}$ I $88 \mathrm{I}-20 \mathrm{IO}$, de 3 de noviembre de $20 \mathrm{II}$ ", Revista de Derecho, n. ${ }^{\circ}$ I, Santiago, 20 I I, Universidad de Chile, pp. 25 I ss.

Dias, Maria Berenice; Eleiene Ferreira Bastos y Naime Márcio Martins Moraes (coords.), Afetos e estruturas familiares, Belo Horizonte, $20 \mathrm{IO}$.

Dulitzky, Ariel E., "Los Tratados de Derechos Humanos en el constitucionalismo iberoamericano", en Thomas Buergenthal y Antônio A. Cançado Trindade (comps.), Estudios especializados de Derechos Humanos, vol. I, San José de Costa Rica, 1996, pp. I 29 ss.

Dulitzky, Ariel E., "La aplicación de los Tratados sobre Derechos Humanos por los tribunales locales: un estudio comparado", en Martín Abregú y Christian Courtis, La aplicación de los Tratados sobre Derechos Humanos por los tribunales locales, Buenos Aires, 1997, pp. 33 ss.

Eguiguren Praeli, Francisco J., Los tribunales constitucionales en Latinoamérica: una visión comparativa, Buenos Aires, 2000.

Escobar Fornos, Iván, "Aplicación de los derechos fundamentales en las relaciones privadas", en Miguel Carbonell, Jorge Carpizo y Daniel Zovatto (coords.), Tendencias del constitucionalismo en Iberoamérica, México, D.F., 2009, pp. I 5 I ss.

Favoreau, Louis, "Le principe de constitutionnalité. Essai de définition d'après la jurisprudence du Conseil constitutionnel", Recueil d'études en hommage à Charles Eisenmann, Paris, 1977.

Ferrajoli, Luigi, "Pasado y futuro del Estado de derecho", Revista Internacional de Filosofía Política, uned-unam, n. ${ }^{\circ}$ i 7 , Madrid-México, D.F., 200 I, pp. 3 I ss.

Ferrajoli, Luigi, "Sobre los derechos fundamentales", en Miguel Carbonell (ed.), Teoría del neoconstitucionalismo, Madrid, 2007, pp. 7 I ss.

Ferrer Mac-Gregor, Eduardo, Los tribunales constitucionales iberoamericanos, México, D.F., 2002.

Figueroa G., Rodolfo, "El matrimonio ante el Tribunal Constitucional", Anuario de Derecho Público, Santiago de Chile, 20 2, Universidad Diego Portales, pp. I 7 ss.

Fix-Zamudio, Héctor, "Algunas tendencias predominantes en el Constitucionalismo latinoamericano contemporáneo", en Ricardo Combellas (coord.), El nuevo Derecho Constitucional latinoamericano, vol. I, Caracas, I996, pp. 43 ss.

Fix-Zamudio, Héctor, "El Derecho Internacional de los Derechos Humanos en las Constituciones latinoamericanas y en la Corte Interamericana de Derechos Humanos", Revista Latinoamericana de Derecho, México, D.F., enero-junio 2004, pp. I4I ss.

García Belaunde, Domingo, "Los tribunales constitucionales en América Latina", Revista de Derecho Político, n. ${ }^{\circ}$ 6r, Lima, 2004, pp. 309 ss. 
Gargarella, Roberto y Christian Courtis, El nuevo constitucionalismo latinoamericano: promesas e interrogantes, CEPAL, Serie Políticas Sociales, n. ${ }^{\circ}$ I 53 , Santiago de Chile, 2009.

Gargarella, Roberto, "El constitucionalismo latinoamericano y la 'sala de máquinas' de la Constitución (I980-2010)”, Gaceta Constitucional, n. ${ }^{\circ} 48$, Lima, 20 I I, pp. 289 ss.

Goldschmidt, Werner, Introducción filosófica al derecho. La teoría trialista del mundo jurídico y sus horizontes, Buenos Aires, I9836.

González Martín, Nuria, "Modelos familiares ante el nuevo orden jurídico: una aproximación casuística”, en Miguel Carbonell, José Carbonell y Nuria González Martín (coords.), Las familias en el siglo XXI: una mirada desde el derecho, México, D.F., 201 2, pp. 57 ss.

Guastini, Riccardo, "Sobre el concepto de constitución”, en Miguel CarboNell (ed.), Teoría del neoconstitucionalismo, Madrid, 2007, pp. 23 ss.

Gudynas, Eduardo, "La ecología política del giro biocéntrico en la nueva Constitución de Ecuador", Revista de Estudios Sociales, n. ${ }^{\circ}$ 32, Bogotá, abril de 2009 , pp. 34 ss.

Guío Camargo, Rosa Elizabeth, "El concepto de familia en la legislación y en la jurisprudencia de la Corte Constitucional colombiana”, Studiositas, n. ${ }^{\circ}$, Bogotá, 2009, pp. 76 ss.

Helmke, Gretchen y Julio Ríos Figueroa (coords.), Tribunales constitucionales en América Latina, México, D.F., 20 го.

Herrera, Marisa, "La noción de socioafectividad como elemento "rupturista" del derecho de familia contemporáneo", Derecho de Familia. Revista Interdisciplinaria de Doctrina y Furisprudencia, n. ${ }^{\circ}$ 66, Buenos Aires, pp. 75 ss.

Kemelmajer de Carlucci, Aída, "El Derecho de Familia en la República Argentina en los inicios del siglo xxi. Su inexorable proceso de constitucionalización y de adecuación a los Tratados internacionales de Derechos $\mathrm{Hu}-$ manos", Revista de Derecho comparado, n. ${ }^{\circ}$ io (Derecho de Familia II), Buenos Aires-Santa Fe, 2005 , pp. 8 ss.

Kemelmajer de Carlucci, Aída, "Las nuevas realidades familiares en el Proyecto de Código civil y comercial argentino”, en Aída Kemelmajer De Carlucci, Daniel Ángel Borrillo y Jesús Flores Rodríguez (coords.), Nuevos desafíos del Derecho de Familia, Buenos Aires, 20 I4, pp. 99 ss.

Lorenzetti, Ricardo, Las normas fundamentales de Derecho privado, Buenos Aires-Santa Fe, I995.

Lorenzetti, Ricardo, Teoría de la decisión judicial. Fudamentos de derecho, Santa Fe-Buenos Aires, 2008.

Llaja Villena, Jeannette y Beatriz Ramírez Huaroto, "Profundizando la igualdad desde la orientación sexual. A propósito de la sentencia de la Corte 
Interamericana de Derechos Humanos del caso Karen Atala e hijas contra Chile", Gaceta Constitucional, n. ${ }^{\circ}$ 54, Lima, 20 I 2 , pp. 32 I ss.

Lloveras, Nora y Marcelo Salomón, El derecho de familia desde la Constitución Nacional, Buenos Aires, 2009.

Marco Navarro, Flavia, Legislación comparada en materia de familias. Los casos de cinco países de América Latina, CePal, Serie Políticas Sociales, n. ${ }^{\circ}$ I49, Santiago de Chile, 2009.

Medici, Alejandro, “Teoría constitucional y giro decolonial: narrativas y simbolismo de la Constitución. Reflexiones a propósito de la experiencia de Bolivia y Ecuador", Gaceta Constitucional, n. ${ }^{4}$ 8, Lima, 20 I I, pp. 329 ss.

Monroy Cabra, Marco Gerardo, “El Derecho internacional como fuente del Derecho constitucional", Anuario Colombiano de Derecho Internacional, n. ${ }^{\circ} \mathrm{I}$, Bogotá, 2008, pp. I07 ss.

Orozco Henríquez, Jesús, "Nuevas tendencias sobre sistema electoral, sistema de partidos y mecanismos de democracia directa en América Latina”, en Miguel Carbonell, Jorge Carpizo y Daniel Zovatto (coords.), Tendencias del constitucionalismo en Iberoamérica, México, D.F., 2009, pp. 227 ss.

Pérez Calvo, Alberto, "Características del nuevo constitucionalismo latinoamericano”, en Claudia Storini y José Alenza García (eds.), Materiales sobre neoconstitucionalismo y nuevo constitucionalismo latinoamericano, Pamplona, 2012 , pp. 32 ss.

Pérez Royo, Javier, "Influencia del constitucionalismo español en el constitucionalismo iberoamericano", en Miguel Carbonell, Jorge Carpizo y Daniel Zovatto (coords.), Tendencias del constitucionalismo en Iberoamérica, México, D.F., 2009, pp. 4r 9 ss.

Pinto, Mónica, "El principio pro homine. Criterio hermenéutico y pauta para la regulación de los Derechos humanos”, en AA.vv., La aplicación de los Tratados sobre Derechos Humanos, Buenos Aires, I997, pp. I63 ss.

Quinche Ramírez, Manuel Fernando y Angélica Armenta Ariza, "Igualdad, razonabilidad y género en los procesos de constitucionalización e internacionalización del derecho”, Estudios Socio-furídicos, n. ${ }^{\circ}$ I 4, Bogotá, 20 I 2, pp. 37 ss.

Ramírez Huaroto, Beatriz, "Los derechos reproductivos en la jurisprudencia de la Corte Interamericana de Derechos Humanos. Apuntes sobre la sentencia en el caso Artavia Murillo y otros contra Costa Rica", Gaceta Constitucional, n. ${ }^{\circ}$ 6 , Lima, 2013 , pp. 366 ss.

Rescigno, Pietro, "Per una rilettura del Codice civile”, Giurisprudenza Italiana, Roma, I968, Parte IV, c. 209 ss.

Rosas Martínez, Alejandro, "Algunas implicaciones jurídicas del matrimonio entre personas del mismo sexo en la Ciudad de México", Revista Derecho del Estado, n. ${ }^{\circ}$ 6, Bogotá, 20 I I, pp. I99 ss. 
Viciano Pastor, Roberto y Rubén Martínez Dalmau, "Fundamentos teóricos y prácticos del nuevo constitucionalismo latinoamericano", Gaceta Constitucional, n. ${ }^{\circ}$ 48, Lima, 201 I, pp. 309 ss.

SAgüés, Néstor P., Elementos de Derecho constitucional, t. I, Buenos Aires, I999³.

Severino Bavio, Paula, "Apuntes de la sentencia del tc sobre familias ensambladas. Una lectura posible de la sentencia del Tribunal Constitucional peruano en el caso Scholz Pérez", Ius (furisprudencia), 3, Lima, 2008, pp. 66 ss.

Vera Mere, Yuri, "La ampliación del Derecho de Familia por obra del Tribunal Constitucional. A propósito de la incorporación de la familia ensamblada y de la concesión de mayores derechos a la familia de hecho", Gaceta del Tribunal Constitucional, n. ${ }^{\circ}$ Io, Lima, abril-junio 2008, pp. 3 ss.

Zavala, Guillermina, "Exigencias de una Derecho de Familia que brinde nuevas respuestas jurídicas", Trabajos del Centro, Centro de Investigaciones de Derecho Civil - unr, Segunda Serie, n. ${ }^{\circ}$ 9/Io, Rosario, 20 I I, pp. 2 I ss.

ZúNiga, Yanira y Susan Turner, "Sistematización comparativa de la regulación de la familia en las constituciones latinoamericanas", Revista de Derecho, Universidad Católica del Norte, año 20, n. ${ }^{\circ}$ 2, Coquimbo, 2013 , pp. 269 ss. 